ECONOMÍA Teoría y PrÁctica • Nueva Época, Número especial, vol. 4, agosto 2018, pp. 125-176, http://dx.doi.org/10.24275/ETYPUAM/NE/E042018/Felix

\title{
Nuevas barreras comerciales de EU a las importaciones automotrices y posibles efectos en el empleo regional*
}

\section{New US Trade Barriers to Automotive Imports and Potential Effects on Regional Employment}

\begin{abstract}
Gustavo Félix Verduzco, ** David Castro Lugo***
$y$ Gilberto Aboites Manrique****

\section{RESUMEN}

La renegociación del TLCAN en los próximos meses es un hecho ineludible y hay temores sobre la imposición de barreras a las importaciones provenientes de México, especialmente en la industria automotriz (IA). Los cambios perturbarían la operación de una industria que funciona con una lógica de competencia global, en la que México es un eslabón para ahorrar costos de producción. Los efectos en el país no serían despreciables, puesto que la IA es de las más dinámicas en el periodo de apertura, con significativas aportaciones a las exportaciones, al PIB y al empleo, especialmente en quince regiones donde la disminución en la IA tendría graves implicaciones sobre el empleo. La presente investigación analiza las posibles consecuencias de nuevas barreras de EU a las importaciones automotrices. El análisis con series de tiempo sobre el empleo de cuatro sectores muestra causalidad a la Granger desde la IA hacia el resto de actividades. Con esa base se utiliza la metodología de modelos VEC y se estiman cuatro escenarios que asumen distintos niveles de reducción de la actividad automotriz. Los resultados indican efectos heterogéneos entre las regiones, afectando con mayor amplitud a las zonas más dependientes de la IA. Además, bajo cada escenario se calcula la magnitud de la pérdida de empleos en todas las actividades económicas.
\end{abstract}

Palabras clave: Industria automotriz; barreras comerciales; empleo regional; modelos VEC. Clasificación JEL: C3, C53, F16, O14, R11.

\begin{abstract}
The renegotiation of NAFTA in the coming months is an inescapable fact and there are fears about the imposition of barriers to imports from Mexico, especially in the automotive industry (AI). The changes would disrupt the operation of an industry that operates with a logic of global competition, in which Mexico is a link to save production costs. The effects in the country would not be negligible since the AI is the most dynamic in the opening period, with significant contributions to exports, GDP and employment, especially in fifteen regions where the decline in AI would have serious implications for jobs. This research analyzes the possible consequences of new us barriers to automotive imports. The analysis with time series on the employment of four sectors shows Granger causality from AI to other activities. With this base, the VEC methodology is used and four scenarios are estimated that assume different levels of reduction of the automotive activity. The results indicate heterogeneous effects between the regions, widely affecting those areas more dependent on AI. Furthermore, under each scenario the magnitude of jobs loss in all economic activities is calculated.
\end{abstract}

Keywords: Automotive industry; Trade barriers; Regional employment; vEC models.

JEL: Classification : C3, C53, F16, O14, R11.

*Fecha de recepción: 30/06/2017. Fecha de aprobación: 31/01/2018.

** Universidad Autónoma de Coahuila. Correo: gustavo.felix@uadec.edu.mx. orciD: 0000-0003-2700-9411.

*** Universidad Autónoma de Coahuila. Correo: david.castro@uadec.edu.mx. orCID: 0000-0003-0130-7197.

***** Universidad Autónoma de Coahuila. Correo: g aboites@yahoo.com.mx. orCID: 0000-0003-1039-8449. 


\section{INTRODUCCIÓN}

La presencia en México de 26 de las más importantes marcas de vehículos ligeros y pesados en el mundo han hecho del país uno de los principales exportadores automotrices, conformando una industria distribuida en 14 entidades federativas (ProMéxico, 2016).

Las armadoras y sus proveedores se complementan y articulan en redes de empresas con distintas localizaciones geográficas, ya sea de la región o de diversos países, llevando a esta industria a un esquema definido por un modelo globalizado, en el cual la competitividad y la eficiencia de los segmentos de producción-distribución que operan alrededor del mundo son de fundamental importancia. Esto explica el desplazamiento de los sistemas integrados por esquemas de provisión externos que, de acuerdo con Sturgeon y Florida (2000) y Ruiz (2015), se caracterizan por ser un conjunto delimitado de grandes proveedores con amplia movilidad de localización internacional.

De esta manera, las armadoras automotrices han descargado muchas tareas en sus proveedores, ${ }^{1}$ permitiendo mayor flexibilidad y socialización de riesgos ante la incertidumbre del mercado, al mismo tiempo que, mediante la conformación de clusters, ${ }^{2}$ reducen costos de transacción, especialmente en transporte y gestión inteligente de inventarios (Aboites, Castro, Félix y Gutiérrez, 2013).

En ese esquema de producción-distribución globalizado, el papel de cada economía es diverso (Sturgeon y Florida, 2000 y Ruiz, 2015). Para el caso de México y otras economías en desarrollo, el bajo costo de la mano de obra ha sido crucial, pues, de acuerdo con Félix y Castro (2015), la atracción del país como productor de autopartes y vehículos está basada no sólo en su ubicación privilegiada al lado de uno de los principales mercados del mundo, sino por el ahorro de costos en los procesos más intensivos en trabajo, ${ }^{3}$ además de aprovechar las facilidades estipuladas en el Tratado de Libre Comercio de América del Norte (TLCAN). Esto no es un

${ }^{1}$ En México operan poco más de mil empresas, de las cuales 345 son de primer nivel, TiER 1, es decir, proveedores de partes originales, principalmente de subensambles, y que tienen capacidad de diseño. TIER 2 y 3 son proveedores de partes con diseños suministrados por TIER 1, que en general abastecen de productos relativamente básicos y partes individuales (Secretaría de Economía, 2012).

${ }^{2}$ Según el Sistema de Información Empresarial Mexicano (SIEM), la cadena productiva de la industria automotriz está compuesta por 44 actividades, empieza por la fabricación de productos de metal y culmina con la comercialización al detalle de vehículos y sus partes. Los principales eslabones se conforman por diez actividades (siete de la rama 336 y tres del comercio al detalle); las 34 restantes son consideradas actividades de apoyo que proveen accesorios y componentes de metal, tela y plástico. https://www.siem.gob.mx/siem/portal/cadenas/CadenasProductivas.asp. 12/06/2017.

${ }^{3}$ Las diferencias salariales de un trabajador sindicalizado, incluyendo sueldo y beneficios, entre México y Detroit es de ocho contra 58 dólares la hora (Durbin, 2017). 
comportamiento exclusivo de la región, pues en otros países con tradición automotriz buena parte de los procesos han sido descentralizados a regiones de bajos costos laborales.

En cualquier caso, la operación de las empresas en clusters automotrices son un elemento central en la dinámica económica regional, esto por la generación directa e indirecta de empleos, por sus efectos de derrama y porque, de acuerdo con Aboites y Castro (2011), transforman el escenario social y cultural de los espacios donde se instalan. Sin embargo, en el caso de México, las regiones receptoras adquirieron al mismo tiempo, condiciones de debilidad estructural porque se vincularon en demasía al destino de esa industria. Así, cuanto mayor es la presencia económica de la industria automotriz (IA), mayor es la dependencia del bienestar de la región hacia el comportamiento económico de esa industria (Valdés 2008; Secretaría de Economía, 2012; Dávila y Escamilla, 2013).

En este documento se pone en evidencia la diversidad regional de la dependencia laboral hacia la IA, para luego analizar la magnitud del efecto que tendría en el empleo una reducción de la producción ocasionada por un rompimiento de la estrategia de competitividad global de las empresas, que podría ocurrir con la renegociación del TLCAN, si se cumplen las declaraciones de Donald Trump en el sentido de establecer barreras a las importaciones, especialmente en la IA, lo cual reduciría las ventajas de la segmentación globalizada.

El énfasis en el empleo se justifica precisamente porque la IA representa actualmente el 15 por ciento del empleo total manufacturero en el país; además, está regionalmente concentrado en 15 zonas urbanas que aglutinan poco más de la mitad del empleo automotriz; zonas que en algunos casos son de baja diversificación, puesto que la actividad manufacturera depende en más del 50 por ciento de esa industria. De ahí pues que cualquier reducción de la actividad automotriz tendría repercusiones en el empleo del país y especialmente en las zonas urbanas donde se concentra.

Para el propósito del análisis, se investiga el posible efecto en el empleo de una reducción en la producción automotriz que resultaría del cambio en la política comercial de EU; en concreto, se realizan predicciones contrafactuales que toman como base metodológica la estimación de modelos VEC (Vectores de Corrección del Error) para cada una de las 15 zonas urbanas con presencia de armadoras automotrices. Con esa base se analizan cuatro escenarios, bajo los cuales, a partir del segundo semestre de 2016, se inducen variaciones exógenas en el empleo automotriz y luego se comparan los efectos en el empleo total. El ejercicio se realiza utilizando la información del Instituto Mexicano del Seguro Social (IMSS) a nivel municipal.

Los resultados evidencian el elevado peso de la IA en la dinámica del empleo de las economías locales; también indican la profundidad de los efectos. En el escena- 
rio más moderado, para el conjunto de las 15 zonas, una reducción exógena del 10 por ciento del empleo automotriz implica dejar de generar poco más de 113,671 empleos en todos los sectores (contrafactual), lo que representa el 93 por ciento de los que realmente se generaron cuando no ocurrió ningún cambio exógeno (factual). Por su parte, en el peor escenario, la reducción exógena implica una disminución total de 221,719 empleos, lo que significa una pérdida equivalente a 1.8 veces el empleo que se genera sin cambio exógeno.

El texto se compone de seis secciones, incluyendo la introducción. En la segunda se sintetizan aspectos teóricos de referencia; la tercera presenta antecedentes y pone en evidencia la importancia de la IA tanto para el país como para las regiones donde se ubica. La cuarta sección explica la metodología utilizada y en la quinta se presentan algunos aspectos relacionados con la validación de los modelos, así como los resultados del análisis de escenarios contrafactuales. Al final se incluyen las principales conclusiones y recomendaciones.

\section{CONSIDERACIONES TEÓRICAS}

De acuerdo con Félix y Castro (2015), la motivación y el funcionamiento de la IA en México es consistente con la teoría de la fragmentación de Jones y Kierzkowoski (1990, 2000 y 2005), quienes utilizan dos conceptos clave: bloques de producción y servicios de vinculación (production blocks y service links). Los bloques refieren a que un bien puede fabricarse combinando varios segmentos, mientras que los servicios facilitan el funcionamiento de cada bloque, así como la interacción entre ellos. Una cuestión relevante es que la producción final se logra al distribuir la localización de los distintos bloques y servicios en regiones de más de un país, esto para aumentar la competitividad, porque se aprovechan las ventajas que resultan de las diferencias internacionales en las dotaciones y costos de factores.

Tal como se argumenta en Félix y Castro (2015), la globalización hace más viable la fragmentación de la producción y ello facilita la integración y apertura comercial de la mayoría de los países, la movilidad internacional del capital financiero y de los factores productivos, la mayor relevancia de las nuevas tecnologías en comunicación e información (especialmente Internet), y todo se conjuga para reducir los costos de vinculación y facilitar la propagación mundial de bloques productivos en la mayoría de bienes manufacturados.

Los procesos de producción en bloques localizados en más de un país también se conocen como redes internacionales de producción-distribución. Kimura, Takahashi y Hayakawa (2007) encuentran que en el sudeste asiático esas redes funcionan en las industrias de maquinaria y equipo, y se caracterizan por la prevalencia de segmentos entrelazados mediante transacciones intra-firma y entre iguales (arms's 
length transactions). En el caso de México, Ruiz (1998) las nombró redes integradoras de producción, formadas a partir de una empresa terminal que descentraliza su producción hacia otras empresas que le manufacturan partes o productos semiterminados para después integrarlos al producto final.

En ese esquema de producción-distribución global son favorables algunas formas específicas de relación entre bloques, en particular el outsourcing y las transacciones entre iguales (Kimura, Takahashi y Hayakawa, 2007), que involucran a varias empresas con administración y gestión independientes, pero que, de acuerdo con Arévalo (1998), mantienen relaciones de colaboración, intercambio de experiencias $\mathrm{y}$, en algunos casos, de apoyo financiero y tecnológico, lo cual se da con el propósito de asegurar el abastecimiento de materiales y componentes.

Félix y Castro (2015) señalan que ese tipo de relaciones son las que están ocurriendo en la IA mexicana, donde se observa la prevalencia de clusters localizados en ciudades con accesibilidad a las principales salidas de exportación (ciudades de la frontera norte y puertos del Pacífico y del golfo de México). De ese modo, de acuerdo con los autores, las empresas automotrices combinan varias ventajas: $a$ ) la importación temporal de maquinaria, equipo, insumos y componentes provenientes de bloques localizados en otros países (facilitado por medio del programa de la Industria Manufacturera, Maquiladora y de Servicios de Exportación, conocido como IMMEX); b) la localización de clusters en la ciudad, o en regiones cercanas, de empresas integradas como proveedores; $c$ ) la accesibilidad para exportar bienes finales o intermedios a bloques de distribución en otros países, y $d$ ) la disposición de fuerza laboral aceptablemente calificada, pero sustancialmente menos costosa que en países desarrollados.

Asumiendo que las plantas armadoras automotrices en México fungen como la industria alrededor de la cual se organiza un conjunto de empresas proveedoras, algunas localizadas local o regionalmente y otras fuera del país, y que la mayoría de las empresas interrelacionadas utilizan procesos intensivos en mano de obra, se plantea que una modificación desfavorable para México de las condiciones comerciales con Estados Unidos (EU), principal destino de las exportaciones automotrices, encarecería la exportación de vehículos y autopartes hacia ese país, lo que tendría efectos no transitorios sobre el empleo y se traduciría directamente en recortes laborales en el sector automotriz e indirectamente en otras industrias relacionadas.

Se plantea, pues, que los efectos de la caída del empleo automotriz se extenderían hacia otros sectores económicos de cada región, principalmente por la interdependencia insumo-producto, pero también por la menor derrama económica al disminuir la masa salarial. El diagrama 1 sintetiza cómo la transmisión de los efectos se da a través de la conexión demanda-producción-empleo. Además, debido a que la distribución geográfica de las armadoras y sus proveedores se localiza principalmente en 
15 zonas urbanas del país, se espera que los efectos de derrama inducidos por la masa salarial tengan mayor alcance en localidades donde ésta se genera.

Diagrama 1. Efectos sobre el empleo del endurecimiento de la política comercial de EU para la importación de vehículos automotores desde México

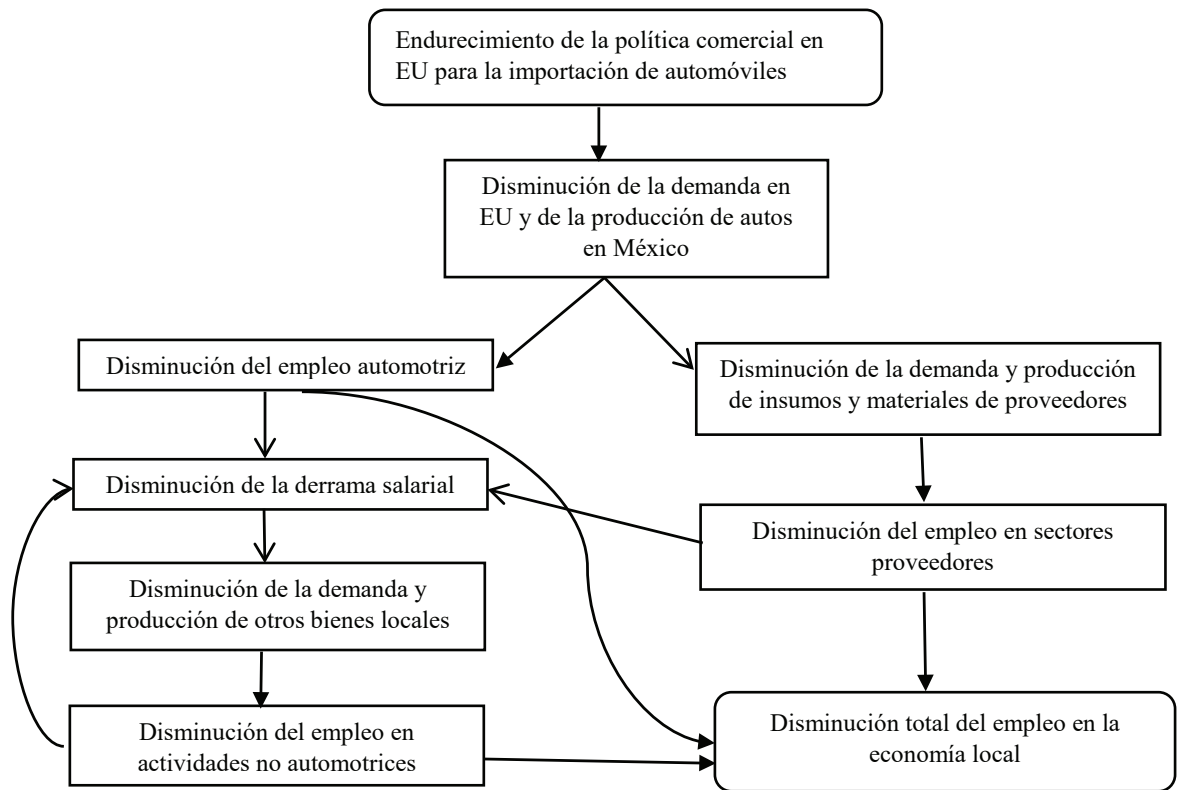

Fuente: elaboración propia.

\section{ANTECEDENTES E IMPORTANCIA DE LA INDUSTRIA AUTOMOTRIZ EN MÉXICO}

De acuerdo con Arévalo (1998), la presencia en el país de compañías automotrices data de 1925, cuando se estableció la primera planta de ensamble de Ford Motor Co.; posteriormente, en 1935 se estableció General Motors; en 1938 lo hizo Automex (que después sería Chrysler); en 1954 se instaló Volkswagen, y, en 1959, NIS$S A N$. Esta primera oleada de empresas tenía en común que su producción estaba destinada totalmente al mercado interno.

A partir de 1962 la IA entra en la dinámica del modelo de sustitución de importaciones, esto como requisito establecido por una serie de decretos dirigidos a esta industria, que obligaban integrar a la producción cierto porcentaje de contenido nacional. ${ }^{4}$ Esto dio pie, según Arévalo (1998), al desarrollo de la industria de auto-

${ }^{4}$ Los detalles de los decretos desde 1962 hasta 1994 pueden consultarse en Aguilar (1994). 
partes, así que durante 1960-1976, para cumplir con los decretos, las empresas ampliaron sus instalaciones de ensamble, plantas de fundición y armadoras de motores, de tal forma que para 1973 el contenido nacional alcanzó 63 por ciento. Sin embargo, tal como lo señalaron Minian y Brown (1997), a pesar del alto contenido nacional, la industria mantuvo su dependencia tanto de maquinaria y equipo como de insumos importados con alto contenido tecnológico.

De acuerdo con Dávila (1997), a principios de los ochenta empezó la instalación de plantas cuya producción tenía como principal destino el mercado de EU; las primeras en el país fueron de General Motors y Chrysler en 1981, en Saltillo y Ramos Arizpe, Coahuila. Así, en 1985, antes del ingreso de México al Acuerdo General sobre Aranceles Aduaneros y Comercio (GATT), había 13 plantas automotrices en el país.

A finales de los ochenta empezaron a disminuir las regulaciones a la IA, lo que se intensificó con el TLCAN a partir de 1994, cuando los requerimientos de contenido local se transformaron a requerimientos de contenido regional provenientes de los tres países socios, lo que dio lugar a que las automotrices externas al área comercial tuvieran incentivos para trasladar bloques de producción a la región, y así cumplir con las reglas de origen y acceder con ventaja al mercado norteamericano. El impacto de estas transformaciones es muy evidente: en 1993, previo al TLCAN, había 15 plantas automotrices; actualmente operan 35 armadoras distribuidas en 14 entidades federativas, ${ }^{5}$ de las cuales 22 están ligadas a la producción de vehículos ligeros y 13 a vehículos pesados.

La importancia de la IA no es sólo por su creciente presencia en la economía del país y de las regiones donde se ubica, sino por sus aportaciones en la generación de empleos directos e indirectos mediante el desarrollo de proveedores; su contribución al PIB y a las exportaciones; los efectos spillover a través de la tecnología (equipos y procesos), la capacitación de personal, y la recaudación fiscal. Debido a estos impactos sobre la economía, la diversidad temática de estudios sobre la IA da muestra de su amplitud como objeto de investigación. ${ }^{6}$

${ }^{5}$ De acuerdo con ProMéxico (2016), las plantas que actualmente existen en el país son: Vehículos ligeros: General Motors (Toluca, Ramos Arizpe, San Luis Potosí y Silao); Ford (Cuautitlán, Hermosillo, Chihuahua); Chrysler-Fiat (Toluca, Ramos Arizpe, Saltillo); Volkswagen (Puebla, Guanajuato); Nissan (Aguascalientes, Cuernavaca); Honda (El Salto); BMw (Toluca); Toyota (Tecate); Mercedes-Benz (Aguascalientes); Mazda (Celaya); Audi (San José Chiapa); Infiniti (Aguascalientes); Kia (Pesquería). Vehículos pesados: Volvo (Tultitlán); Freightliner (Santiago Tianguistenco, Saltillo); ISUZu (San Martín Tepetlixpan); Hyundai (Querétaro); Scania (Querétaro); MAN-VW (Querétaro); DINA (Ciudad Sahagún); Kenworth (Mexicali); International (Escobedo); Mercedes-Benz (García); HINO (Silao). Motores para vehículos pesados: Cummins y Detroit Diesel (San Luis Potosí).

${ }^{6} \mathrm{La}$ amplitud de estudios abarca aspectos tales como los temas del libro coordinado por Álvarez 
132 ECONOMÍA TeOría y PrÁCTICA • Nueva Época, Número especial, vol. 4, agosto 2018

Tal como lo establecen Carbajal y Del Moral (2014), es indudable que la dinámica de la IA en México está ligada al proceso de integración comercial con América del Norte. El incremento de las plantas automotrices en el periodo posterior al TLCAN así lo certifica; los datos de los censos económicos también arrojan evidencia en esa dirección: en 1993 la IA representaba el 5.2 por ciento del personal ocupado y el 9.2 por ciento del valor agregado manufacturero; para 2003, las proporciones fueron 12.2 y 17.1 por ciento; en 2013 las cifras aumentaron al 15.3 y 21.7 por ciento, respectivamente. Además, de acuerdo con AMIA (2017), en 2016 las exportaciones de vehículos ligeros y de camiones hacia América del Norte representaron en promedio el 82 y 87 por ciento respectivamente, siendo la mayor parte hacia EU (en promedio el 72 por ciento).

Un rasgo característico de la actividad automotriz es su distribución espacial, lo cual, como se ha dicho en este documento, obedece a la accesibilidad vía terrestre tanto a la frontera de EU como hacia los puertos marítimos del Pacífico y del Golfo de México. Así, aunque en todas las entidades se registra personal ocupado en esa actividad, en realidad la mayor concentración se da en 14 entidades y, de manera particular, en las 15 zonas urbanas con armadoras automotrices. ${ }^{7}$

La gráfica 1 muestra que el empleo automotriz está altamente concentrado en las 15 zonas con armadoras. Aun cuando la tendencia a partir de 2012 es decreciente, estas regiones aglutinan más del 50 por ciento del total en el país. También se observa que esas zonas concentran gran parte del empleo total y manufacturero, 35 y 45 por ciento, respectivamente; sin embargo, la región en su conjunto se especializa en la IA.

La especialización automotriz se refleja también en la gráfica 2: en el conjunto de las 15 zonas urbanas más de la quinta parte del empleo manufacturero se genera en esa industria, lo cual difiere con el resto del país, donde el empleo automotriz es poco más del 15 por ciento. La dinámica creciente del empleo manufacturero, espe-

et al. (2014) sobre el auge reciente de la industria automotriz en México, con estudios de diferentes autores sobre reestructuración productiva, efectos de la crisis, articulación institucional, estudios comparativos con otros países, propiedad intelectual, sindicalización e innovación de proveedores. Otro libro coordinado por Covarrubias et al. (2016) presenta estudios de caso realizados por diversos autores sobre relaciones de empleo y culturas organizacionales en la industria automotriz en México. Estudios sobre reestructuración productiva (Millones, 2012); encadenamientos y estudios de clusters (Covarrubias, 2014; Galicia-Bretón y Sánchez-Juárez, 2011); acuerdos comerciales (Carbajal y del Moral, 2014), por mencionar algunos de los más recientes.

${ }^{7}$ Aguascalientes (capital), Baja California Norte (Tecate-Tijuana y Mexicali), Chihuahua (capital), Coahuila (Saltillo-Ramos Arizpe), Guanajuato (Silao-Celaya-León), Hidalgo (Ciudad Sahagún), Jalisco (El Salto), Estado de México (Toluca-Cuautitlán-San Martín Tepetlixpan), Morelos (Cuernavaca), Nuevo León (Escobedo, García y Pesquería), Puebla (capital-San José Chiapa), Querétaro (capital), San Luis Potosí (capital), Sonora (Hermosillo). 
cialmente en las 15 zonas urbanas, es claramente conducida por la dinámica de la IA: durante la crisis de 2008-2009 el mayor efecto se dejó sentir en esa industria; posteriormente, a partir de 2009 recuperó la tendencia ascendente, reflejando superioridad frente al total de la manufactura.

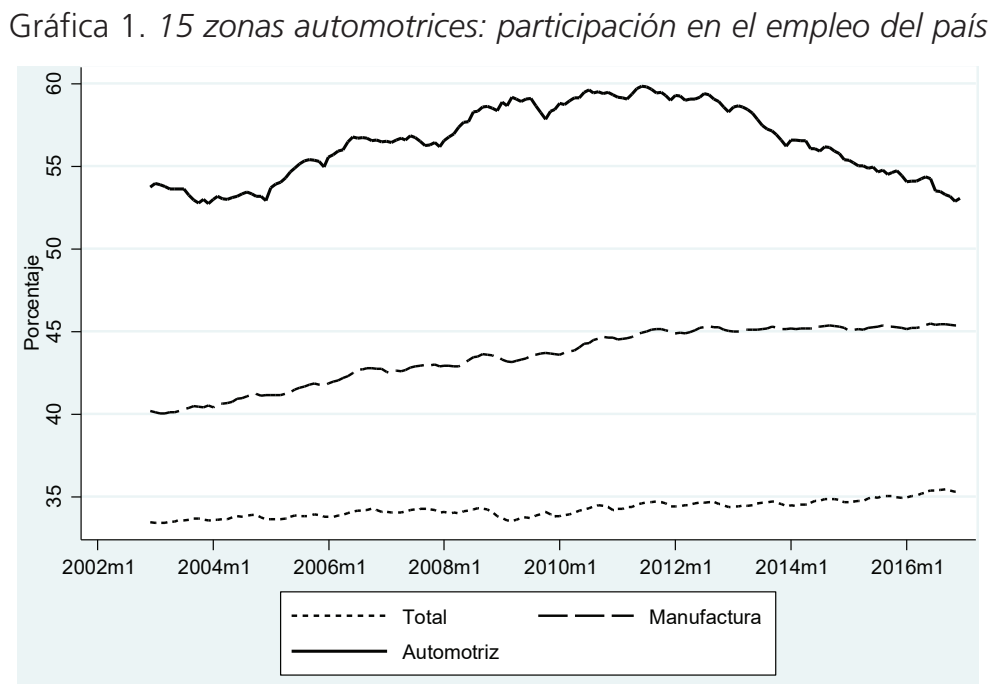

Fuente: Elaborado con información de trabajadores asegurados en el ImsS.

Gráfica 2. Proporción del empleo automotriz en el empleo manufacturero

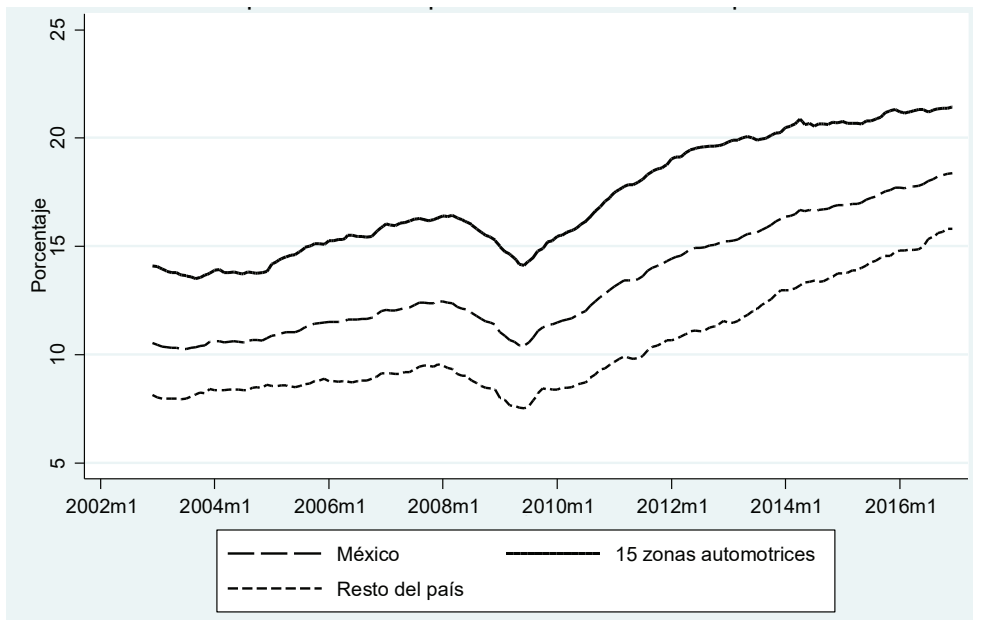

Fuente: Elaborado con información de trabajadores asegurados en el ımss. 
Entre las 15 zonas urbanas se observan diferentes grados de dependencia hacia la IA. En la gráfica 3 sobresalen Ciudad Sahagún y Saltillo-Ramos con más del 50 por ciento del empleo manufacturero en esa industria. Luego, en un segundo grupo, integrado por Aguascalientes, Puebla, Querétaro y San Luis Potosí, cada zona aglutina en ese sector entre el 30 y 40 por ciento del empleo manufacturero. En Chihuahua, Silao-Celaya-León, Estado de México, Cuernavaca, Monterrey, Hermosillo y Mexicali, el empleo de la IA está entre el 20 y 30 por ciento. Del grupo de regiones analizadas, Tijuana-Tecate y Guadalajara son alta y medianamente manufactureras, aunque en éstas el peso del empleo automotriz apenas rebasa el 5 por ciento.

Gráfica 3. Dependencia regional al empleo automotriz

Diciembre de cada año

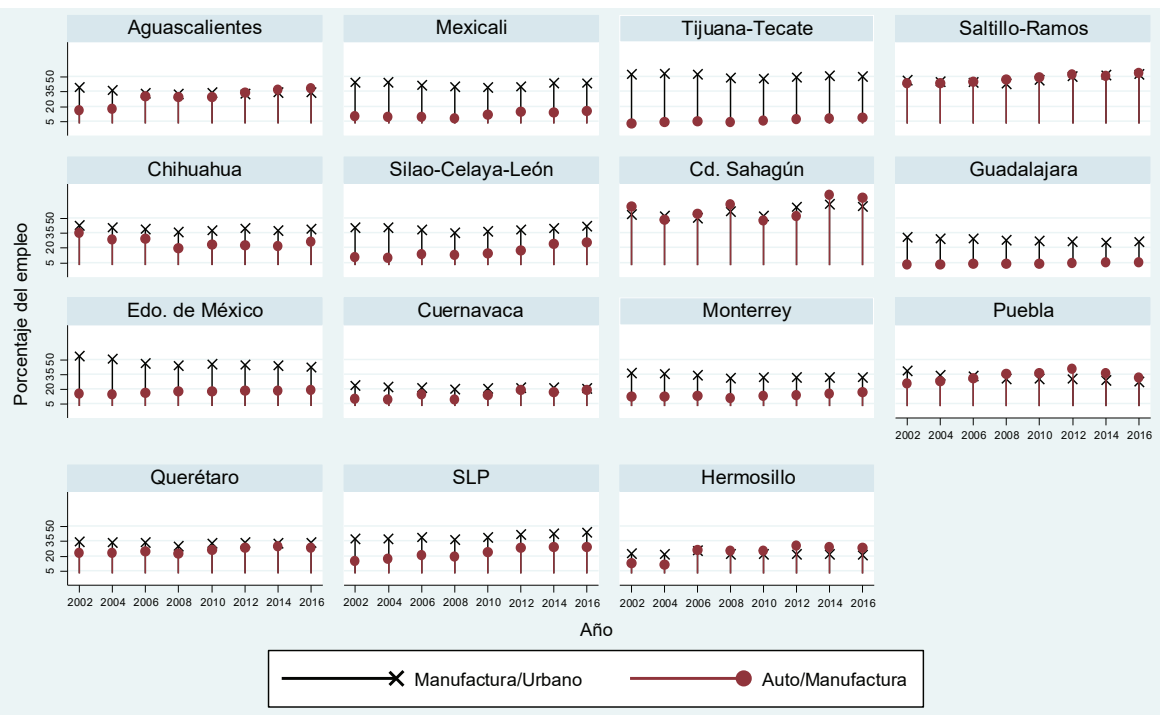

Fuente: Elaborado con información de trabajadores asegurados en el ıмss.

Debido a los diferentes niveles de concentración del empleo automotriz en cada región, se espera que ante el eventual endurecimiento de la política comercial de EU, las regiones más afectadas sean aquellas con mayor grado de dependencia. La gráfica 4 muestra que el empleo de la IA es el más sensible al desempeño económico de EU, prueba de ello es que tanto la crisis de 2008-2009 como la posterior recuperación económica de ese país se reflejó con mayor intensidad en ese sector. Es interesante corroborar que desde el segundo semestre de 2009 el empleo automotriz ha tenido un crecimiento sin precedentes. 
Gráfica 4. Índices de empleo en 15 zonas urbanas de México y de producción industrial en Estados Unidos (2012=100)

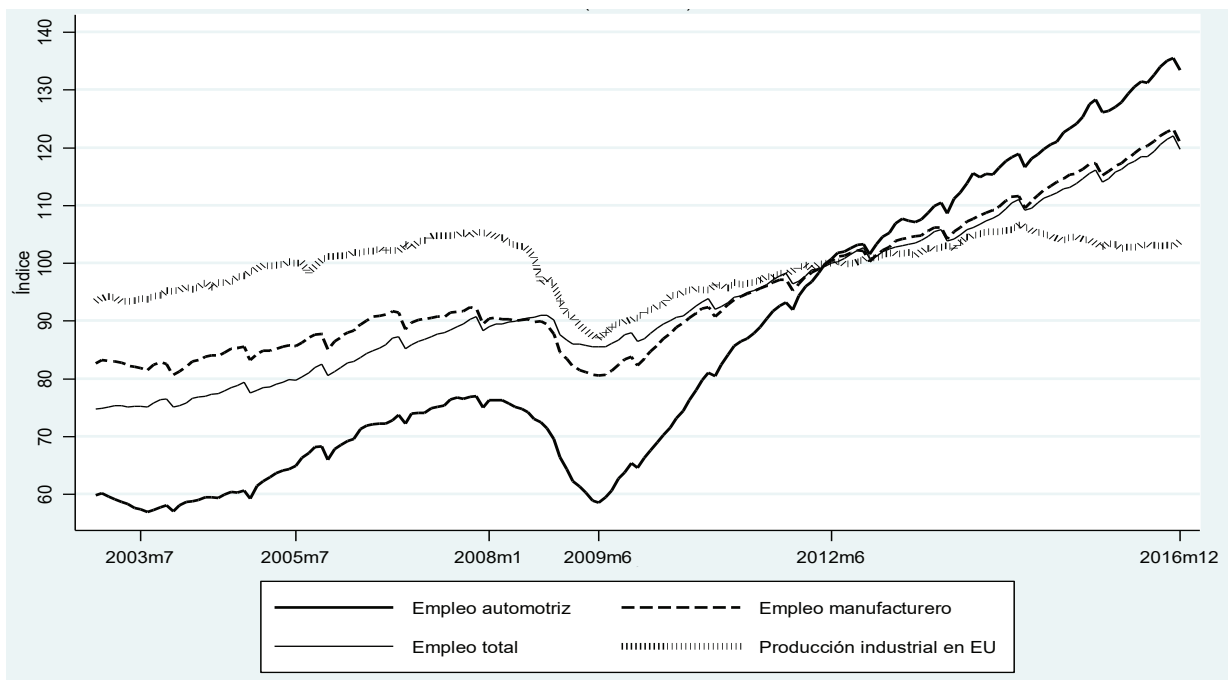

Fuente: Elaborado con información de trabajadores asegurados en el Imss y del Banco de la Reserva Federal de EU.

Los efectos de la crisis estadounidense se dejaron sentir de manera heterogénea en las 15 zonas urbanas analizadas. Con las excepciones de Ciudad Sahagún, Puebla y Hermosillo, la mayor magnitud del efecto se registró en el sector automotriz (cuadro 1). En el agregado de las zonas el empleo en este sector cayó 23.6 por ciento. Las manufacturas afectadas en segundo lugar son aquellas que incluyen actividades de $\mathrm{MAN1}^{8}$ (12.5 por ciento); luego, el resto de actividades manufactureras (MAN2, con 6.7 por ciento), y en menor medida las actividades del terciario ( 2.5 por ciento). Estos hechos muestran que la relación de dependencia del empleo hacia la economía de EU se da mediante el sector manufacturero y de manera significativa a través de la IA. En términos porcentuales, las tres zonas automotrices más afectadas fueron Cuernavaca, Chihuahua y Querétaro. En términos absolutos, las que perdieron mayor empleo automotriz fueron Monterrey, Chihuahua y Coahuila. Saltillo-Ramos en

\footnotetext{
${ }^{8}$ Para el análisis con la información del IMSS se consideraron cuatro sectores: tres particiones de la industria manufacturera y el agregado de las actividades de comercio y servicios (terciario). Las particiones de la industria manufacturera son: $a$ ) industria automotriz (Auto); $b$ ) MAN1, que incluye: fabricación de productos de hule y plástico; industrias metálicas básicas; fabricación de productos metálicos; fabricación de maquinaria, equipo y sus partes; fabricación de maquinaria, aparatos y equipos eléctricos-electrónicos, y c) MAN2, que incluye al resto de actividades manufactureras.
} 
Man1. Destacan Tijuana-Tecate con más de 30 mil empleos perdidos, Monterrey con poco más de 15 mil y Guadalajara con 12 mil. Estas tres regiones incluso perdieron más empleos en este tipo de manufactura que en la industria automotriz.

Cuadro 1. Zonas automotrices:

cambios en el empleo durante la crisis de 2008-2009

\begin{tabular}{|c|c|c|c|c|c|c|c|c|c|c|}
\hline ZONA & TOTAL & $\%$ & AUTO & $\%$ & Man1 & $\%$ & MAN2 & $\%$ & TERCIARIO & $\%$ \\
\hline Aguascalientes & $-12,980$ & -7.5 & $-3,488$ & -18.5 & $-1,314$ & -12.1 & $-1,471$ & -4.7 & $-6,707$ & -6.0 \\
\hline Mexicali & $-13,030$ & -8.0 & $-1,672$ & -26.1 & $-9,907$ & -21.5 & -958 & -4.5 & -494 & -0.6 \\
\hline Tijuana-Tecate & $-43,303$ & -11.9 & $-1,774$ & -20.9 & $-30,197$ & -20.8 & $-7,611$ & -16.5 & $-3,721$ & -2.3 \\
\hline Saltillo-Ramos & $-13,563$ & -9.2 & $-7,688$ & -21.5 & $-1,531$ & -8.8 & $-2,363$ & -11.5 & $-1,982$ & -2.7 \\
\hline Chihuahua & $-13,617$ & -8.1 & $-8,955$ & -46.0 & -715 & -2.5 & $-2,585$ & -12.1 & $-1,362$ & -1.4 \\
\hline Silao-Celaya-León & $-7,226$ & -2.1 & $-4,201$ & -20.9 & $-1,486$ & -5.7 & $-6,021$ & -6.4 & 4,482 & 2.1 \\
\hline Cd. Sahagún & $-1,079$ & -16.1 & -741 & -24.5 & -470 & -46.3 & 51 & 11.8 & 80 & 3.6 \\
\hline Guadalajara & 7,870 & 0.9 & $-1,218$ & -11.5 & $-12,279$ & -10.4 & $-9,417$ & -6.6 & 30,784 & 5.2 \\
\hline Edo. de Méx. & $-9,392$ & -3.4 & $-6,043$ & -23.9 & $-2,761$ & -7.7 & 369 & 0.5 & -957 & -0.7 \\
\hline Cuernavaca & 407 & 0.4 & $-1,964$ & -50.0 & -309 & -4.0 & 243 & 1.6 & 2,436 & 2.8 \\
\hline Monterrey & $-11,066$ & -1.2 & $-11,977$ & -27.0 & $-15,547$ & -9.3 & $-6,924$ & -5.4 & 23,382 & 4.0 \\
\hline Puebla & $-4,396$ & -1.6 & $-3,371$ & -10.5 & $-2,800$ & -13.9 & $-3,673$ & -8.2 & 5,449 & 3.1 \\
\hline Querétaro & $-3,899$ & -1.7 & $-7,206$ & -32.6 & $-1,619$ & -4.7 & $-3,770$ & -13.9 & 8,696 & 6.2 \\
\hline San Luis Potosí & $-12,264$ & -6.6 & $-4,429$ & -25.5 & $-3,356$ & -10.9 & $-2,646$ & -8.6 & $-1,834$ & -1.7 \\
\hline Hermosillo & 3,847 & 3.1 & -386 & -4.5 & $-3,823$ & -28.9 & -891 & -6.5 & 8,947 & 10.3 \\
\hline Totales & $-133,690$ & -3.1 & $-65,112$ & -23.6 & $-88,112$ & -12.5 & $-47,666$ & -6.7 & 67,200 & 2.5 \\
\hline
\end{tabular}

Nota: se contabiliza el cambio en el empleo ocurrido entre junio de 2008 y junio de 2009.

Fuente: elaboración propia con base en estadísticas de empleo del ıMss.

Considerando los antecedentes presentados en esta sección, se resumen tres elementos escenciales de la IA en México: $i$ ) la integración comercial con Norteamérica ha sido el parteaguas determinante de la extraordinaria dinámica de esa industria en lo que va del presente siglo; ii) la importancia del mercado de eu, el establecimiento de las reglas de origen, conjugados con la lógica productiva global que aprovecha la segmentación de procesos localizables en función de ventajas comparativas y absolutas, dentro de las cuales para México son escenciales los costos laborales, pero también la cercanía y la accesibilidad al principal consumidor de vehículos en el mundo, y, iii) en atención a la accesibilidad, la distribución espacial de las armadoras y sus proveedores se ha focalizado en 15 zonas urbanas, las cuales muestran una alta, pero diversa dependencia de sus economías locales hacia la IA, especialmente en el empleo. 
Respecto de los estudios referentes a la IA, se aprecia una preocupación permanente por analizar e interpretar las transformaciones que esta industria presenta, así como por la respuesta de la misma a los retos que imponen los factores coyunturales o estructurales tanto internos como externos. Es pertinente resaltar la insuficiencia de investigaciones sobre los posibles efectos en el empleo regional debido a modificaciones en la política comercial de EU, especialmente las que se refieren al sector automotriz. Aunque debe mencionarse que Carbajal, Almonte y Mejía (2016) estudian y encuentran causalidad entre la producción de la IA y del sector manufacturero regional (cuatro grupos de estados); sin embargo, no focalizan en micro regiones, ni en los efectos sobre el empleo.

\section{MetodologíA}

Con el objetivo de realizar predicciones contrafactuales, se estimaron modelos de Vectores de Corrección del Error (VEC) para cada una de las 15 zonas, utilizando para ello la metodología basada en Máxima Verosimilitud desarrollada por Johansen $(1988,1991$ y 1995). En nuestro caso, cada vector contiene como variables el logaritmo del empleo de las actividades Auto, MAN1, MAN2 y Terciario, para cada zona y 169 observaciones mensuales $(2002 \mathrm{~m} 12$ a $2016 \mathrm{~m} 12)$. Siguiendo a Johansen (1995), el modelo a estimar para cada zona queda representado por la ecuación:

$$
\Delta y_{t}=\alpha\left(\beta y_{t-1}+\mu+\rho t\right)+\sum_{i=1}^{p-1} \Gamma_{i} \Delta y_{t-i}+\gamma+\tau t+\varepsilon_{t}
$$

Donde $y_{t}$ es el vector de variables endógenas (en logaritmos); $\Delta$ representa el cambio de uno a otro periodo; $\beta$ es la matriz de parámetros de largo plazo en las ecuaciones de cointegración; $\alpha$ es el vector de parámetros que corrigen las desviaciones del equilibrio; $\mu$ y $\gamma$ son, respectivamente, términos constantes de la ecuación de cointegración y de los efectos de corto plazo; $t$ es una variable que incorpora la tendencia, $\rho$ y $\tau$ son los vectores de parámetros de las tendencias en la ecuación de cointegración y en la parte diferenciada; $\Gamma_{i}$ son las matrices de parámetros asociados a los efectos de corto plazo y $\varepsilon_{t}$ es un vector estocástico con ruido blanco gaussiano.

Siguiendo a Johansen, la propuesta del modelo VEC se justifica después de confirmar, primero, que para cada zona las variables son procesos con raíz unitaria, I(1), $\mathrm{y}$, segundo, que la combinación lineal de las variables en cada vector arrojan procesos estacionarios. Para los contrastes de raíz unitaria se realizaron las pruebas Phillips-Perron y de Dickey-Fuller aumentado. El rango de cointegración se obtuvo utilizando los contrastes de Johansen basados en el estadístico de la traza. Previamente se había determinado la extensión de los rezagos mediante la estimación de vectores autorregresivos (VAR), utilizando para ello los criterios de información de Akaike, Bayesiano 
de Schwarz y de Hannan y Quinn. Cuando se obtuvo el rango de cointegración se determinó también si la combinación lineal de largo plazo era estacionaria con o sin tendencia y/o alrededor de una media igual o distinta de cero. Al estimar la ecuación (1), cada zona resultó con distinto rango de cointegración y dinámica de corto y largo plazo. La ecuación estimada para cada zona se resume en el cuadro 2.

Cuadro 2. Ecuación (1) estimada para cada zona

\begin{tabular}{|c|c|c|c|}
\hline PARÁMETROS RESTRINGIDOS & RANGO DE COINTEGRACIÓN & $\begin{array}{c}\text { REZAGOS EN LOS EFECTOS } \\
\text { DE CORTO PLAZO }\end{array}$ & ZONA \\
\hline \multirow{4}{*}{$\tau=0$} & 2 & 4 & Saltillo-Ramos \\
\hline & 1 & 1 & Guadalajara \\
\hline & 3 & 1 & Monterrey \\
\hline & 1 & 2 & Cd. Sahagún \\
\hline \multirow{2}{*}{$\begin{array}{l}\tau=0 \\
\rho=0\end{array}$} & 2 & 2 & Puebla \\
\hline & 1 & 2 & Tijuana-Tecate \\
\hline \multirow{9}{*}{$\begin{array}{l}\tau=0 \\
\rho=0 \\
\gamma=0\end{array}$} & 1 & 2 & Aguascalientes \\
\hline & 2 & 3 & Mexicali \\
\hline & 1 & 1 & Chihuahua \\
\hline & 2 & 2 & Silao-Celaya-León \\
\hline & 1 & 3 & Querétaro \\
\hline & 2 & 1 & Cuernavaca \\
\hline & 1 & 3 & Hermosillo \\
\hline & 1 & 3 & Edo. Méx. \\
\hline & 1 & 3 & San Luis Potosí \\
\hline
\end{tabular}

Fuente: elaboración propia con base en estimaciones econométricas.

Continuando con la metodología, una vez estimados los modelos, se procedió a validar la no autocorrelación serial de los residuos (prueba LM de Johansen); su normalidad (Prueba Jarque-Bera), así como la condición de estabilidad, esto último verificando que los valores propios y módulos de la matriz de acompañamiento sean menores a la unidad.

Debido al propósito de realizar pronósticos contrafactuales, el siguiente paso fue verificar la existencia de causalidad a la Granger. Para ello se utilizó la propuesta Geweke- Hosoya, en la versión desarrollada por Breitung y Candelon (2006), mediante la cual se contrasta la causalidad en todas las frecuencias (espectral), con lo que se pudo determinar también la amplitud de onda. Con esto se verificó la predictibilidad con distintas duraciones de tiempo (largo plazo o fluctuaciones con distinta duración). Los resultados de este análisis se presentan en la gráfica A1 del apéndice. ${ }^{9}$

${ }^{9}$ Los resultados de este análisis muestran que, en general, el empleo automotriz causa a la Granger tanto al empleo del sector Terciario, MAN1 y MAN2. Esto salvo en las zonas de Guanajuato, 
El último proceso de validación consistió en utilizar las ecuaciones correspondientes a cada zona para realizar predicciones contrafactuales endógenas a partir de julio de 2016; con esto se verificó que las series realmente observadas estuvieran contenidas en un intervalo de predicción del 95 por ciento. Los resultados pueden consultarse en la gráfica A2 del apéndice. La metodología en su conjunto se resume en el diagrama 2.

\section{Diagrama 2. Resumen de la metodología utilizada para la estimación de escenarios}

Variables en niveles (logaritmo): Empleo mensual desestacionalizado para cada sector y zona urbana. Sectores: Automotriz, Manufactura 1, Manufactura 2 y Terciario

Zonas urbanas: Aguascalientes, Mexicali, Tijuana-Tecate, Saltillo, Chihuahua, Celaya-León, Hidalgo, Guadalajara, Toluca, Cuernavaca, Monterrey, Puebla, Querétaro, San Luís Potosí y Hermosillo

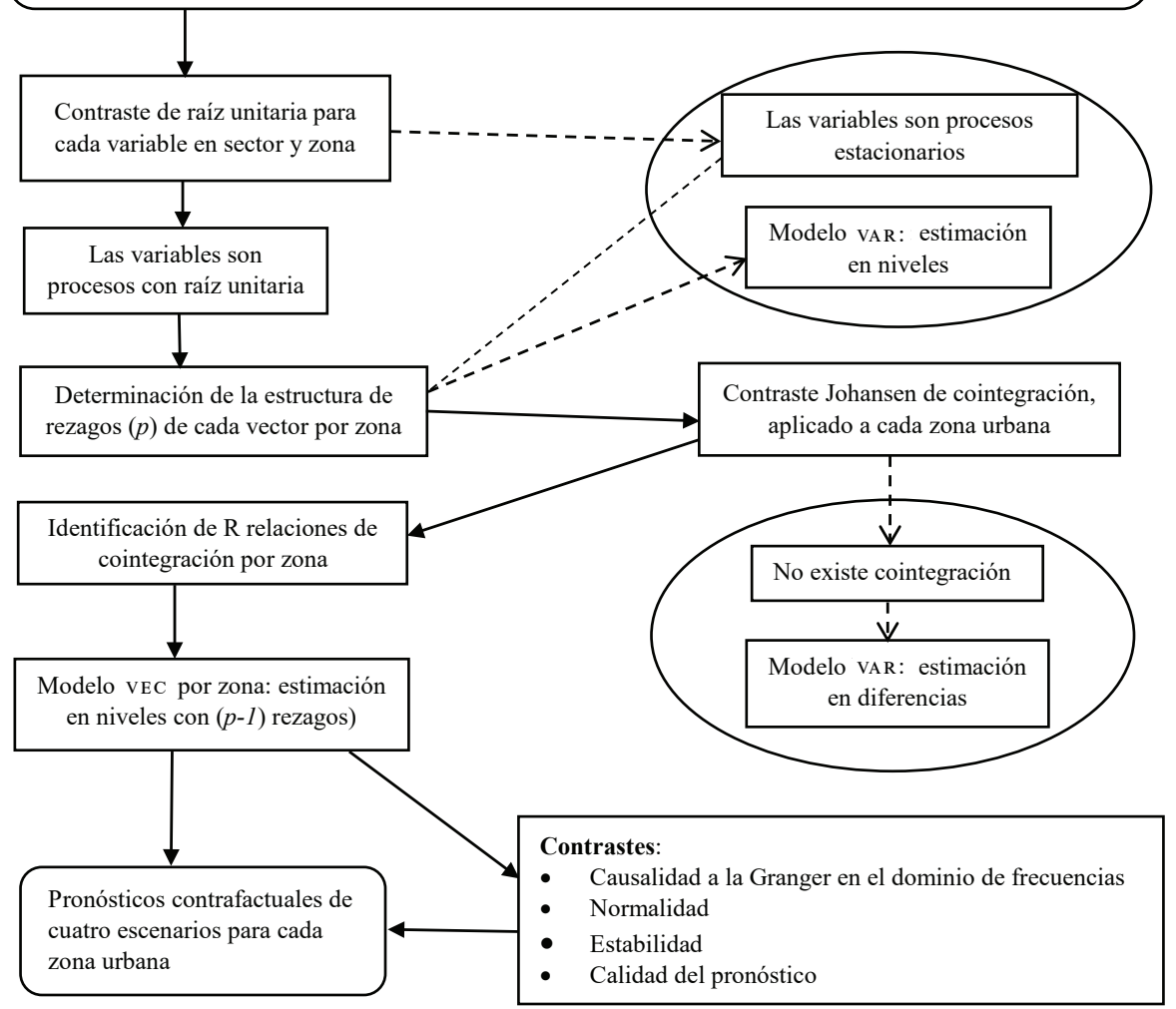

Nota: Los procesos encapsulados en elipses no fueron requeridos.

Puebla y Guadalajara en las actividades MAN2, y de Tijuana-Tecate para las actividades MAN1 (gráfica A1 del apéndice). 


\section{ANÁLISIS DE ESCENARIOS CONTRAFACTUALES}

Con base en las estimaciones del modelo VEC correspondiente a cada zona urbana (cuadro 2), bajo los primeros tres escenarios se induce una variación exógena en el empleo de la IA, después, los cambios resultantes en el empleo de todos los sectores son comparados, primero, con los cambios realmente observados durante el semestre y luego contra el nivel de empleo al final del periodo. En el cuarto escenario se analizan los efectos de inducir cambios exógenos simultáneos en el sector automotriz y en las actividades de MaN1.

En todos los escenarios se asume que las disminuciones exógenas se distribuyen en tiempo de manera homogénea durante los últimos seis meses de 2016. El primer escenario supone que el empleo de la IA disminuye 10 por ciento en el semestre. Los últimos tres escenarios se basan en la caída del empleo durante la crisis de 2008-2009 (cuadro 1): el segundo asume que el empleo automotriz disminuye en un porcentaje equivalente al observado en cada zona durante la crisis; el tercero induce una disminución igualitaria del 23.6 por ciento en el empleo de la IA, porcentaje que equivale al total de las 15 zonas durante la crisis; el cuarto escenario combina disminuciones igualitarias del 23.6 por ciento en el sector automotriz y del 12.5 por ciento en las actividades MAN1. ${ }^{10}$

El análisis supone que las variaciones exógenas en el empleo automotriz (así como en MAN1 bajo el escenario 4) se dan como una reacción originada por al aumento del proteccionismo en EU, lo cual ocasiona incremento de costos y a su vez disminución de la producción en México. Esto no significa que las variaciones del empleo sean inmediatas a la modificación de la política comercial, sino que podrían ser graduales en un periodo de tiempo determinado. Se les considera exógenas por ser una respuesta ajena a la interdependencia del modelo. Tampoco se espera que las variaciones del empleo sean de la misma magnitud, ni simultáneas en todas las zonas urbanas, lo cual obedece a las diferencias regionales en marcas, modelos y en la composición de los mercados.

Bajo estas consideraciones, para efecto de realizar predicciones concretas, se asume que el proceso inicia en el momento en el que se dan los cambios exógenos en el empleo del sector automotriz; ${ }^{11}$ a partir de ahí, mediante la interacción de los efectos entre las variables del modelo, automáticamente se efectúan los ajustes en el resto de los sectores.

\footnotetext{
${ }^{10} \mathrm{Ambos}$ corresponden al total de las 15 zonas durante la crisis.

${ }^{11}$ A excepción del escenario 4, donde la disminución del empleo automotriz ocurre simultáneamente con la caída del empleo en MAN1.
} 
En cada zona el tamaño del ajuste en empleo de todos los sectores va a depender, en primer lugar, del peso relativo del empleo en el sector automotriz, lo cual se traduce en derrama salarial que, mediante el consumo, afecta la dinámica de otras actividades económicas; en segundo lugar, del grado de interdependencia por las relaciones insumo-producto entre la IA y otras actividades económicas de la región. Las respuestas de ajuste correspondientes al escenario 2 se muestran en la gráfica 5, donde se observa que el efecto de una reducción exógena del empleo automotriz afecta en la misma dirección a todos los sectores considerados. Las excepciones son Puebla, Cuernavaca y Mexicali en las actividades de MAN2, que son las que se espera guarden menor interdependencia con la IA.

Se observa también que, en general, el mayor impacto es sobre las actividades que más se relacionan como proveedores de la IA (MAN1, que incluye: fabricación de productos de hule y plástico; industrias metálicas básicas; productos metálicos; maquinaria, equipo y sus partes; maquinaria, aparatos y equipos eléctricos-electrónicos). En este sector las reacciones se magnifican especialmente en las zonas con mayor concentración automotriz (Saltillo, Aguascalientes, Estado de México, Querétaro, Silao-Celaya-León y Monterrey). (Véase gráfica 5).

Los resultados en el empleo total después de realizar las predicciones para cada escenario se muestran en los cuadros 3 y 4 . El primero compara los cambios en el empleo realmente observados durante el segundo semestre de 2016, contra aquellos que resultan en cada escenario. ${ }^{12} \mathrm{El}$ segundo compara los niveles del empleo total de cada escenario con respecto del nivel observado a diciembre de 2016.

Las estimaciones evidencian el elevado peso de la IA en la dinámica del empleo en las economías locales. También indican la profundidad de los efectos del posible endurecimiento de la política comercial de EU. El cuadro 3 muestra que, sin ningún efecto exógeno, durante el segundo semestre de 2016, en el agregado de las 15 zonas urbanas se generaron 122,476 nuevos empleos (factual). Sin embargo, el escenario más moderado (contrafactual), que supone una disminución igualitaria del 10 por ciento en el empleo automotriz de cada zona, implica que durante ese periodo los nuevos empleos en todos los sectores serían sólo 8,805. El efecto significó dejar de generar poco más de 113,671 puestos de trabajo, lo que equivale a perder casi el 93 por ciento del nuevo empleo factual. Otra forma de verlo es a través de la tasa de crecimiento del último semestre: sin cambio exógeno el empleo total creció 2.1 por ciento, mientras que en el contrafactual se registra un crecimiento de sólo 0.15 por ciento. Por su parte, el cuadro 4 muestra que al final del periodo el empleo contrafactual total equivaldría al 98.1 por ciento del factual.

\footnotetext{
${ }^{12}$ Los resultados para cada sector se incluyen en los cuadros A1-A4 del apéndice.
} 
142 ECONOMÍA TeOrÍA y PrÁCTICA • Nueva Época, Número especial, vol. 4, agosto 2018

Gráfica 5. Escenario 2: Efectos de una reducción exógena del empleo automotriz, equivalente a la crisis 2008-2009
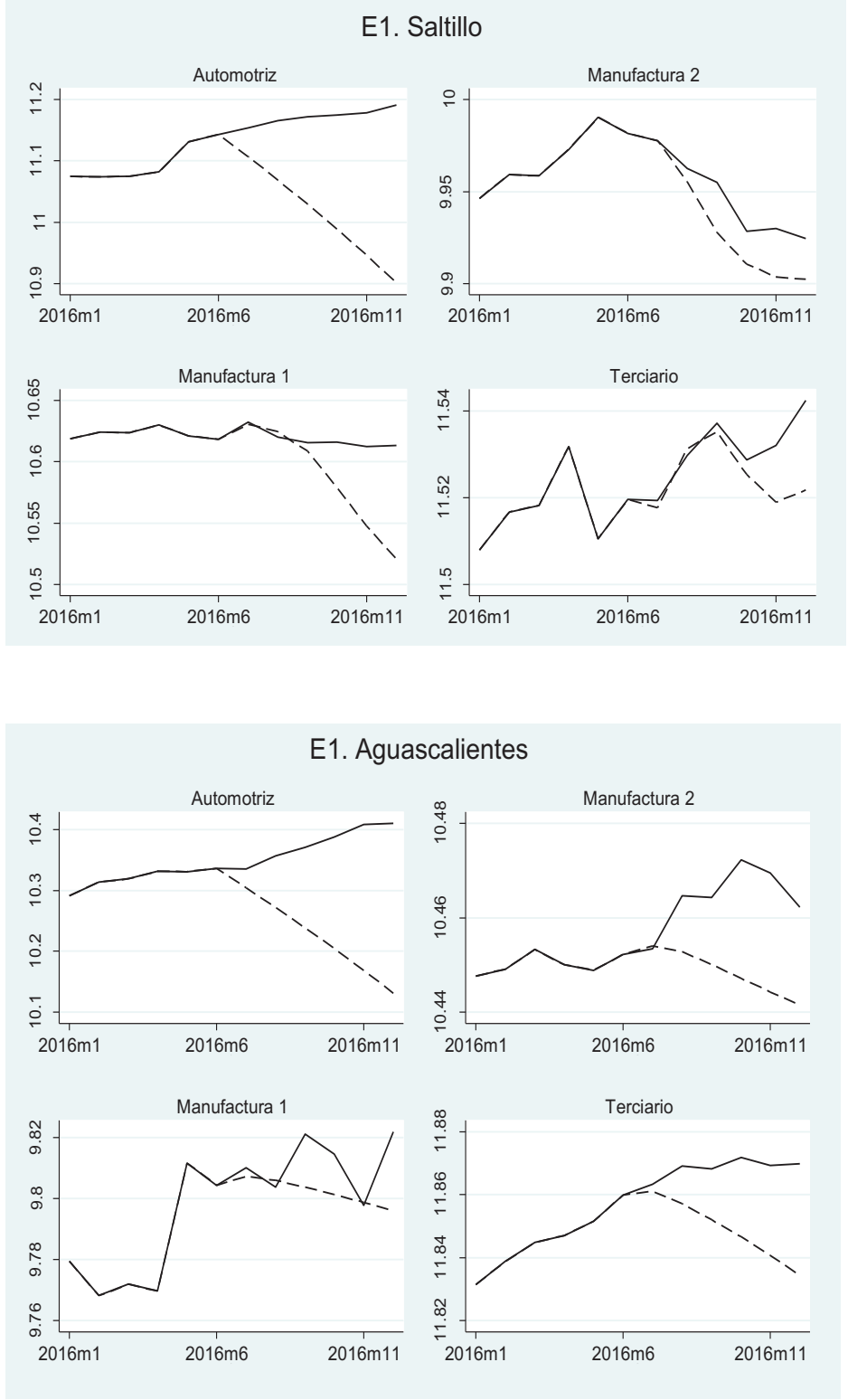

Logaritmo natural del empleo. Observado —_ Escenario 2 ------. 


\section{E1. Zonas del Estado de México}
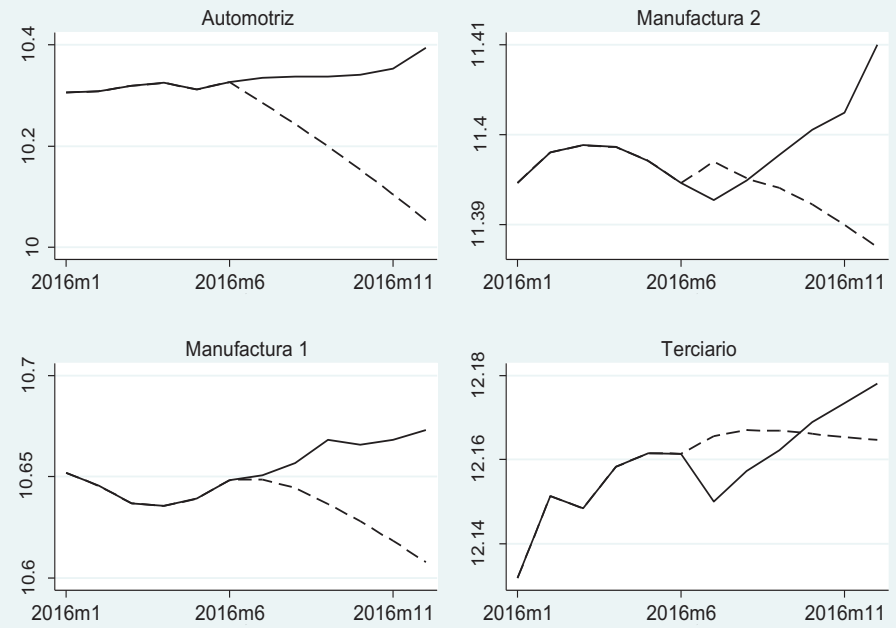

E1. Irapuato-Celaya-León
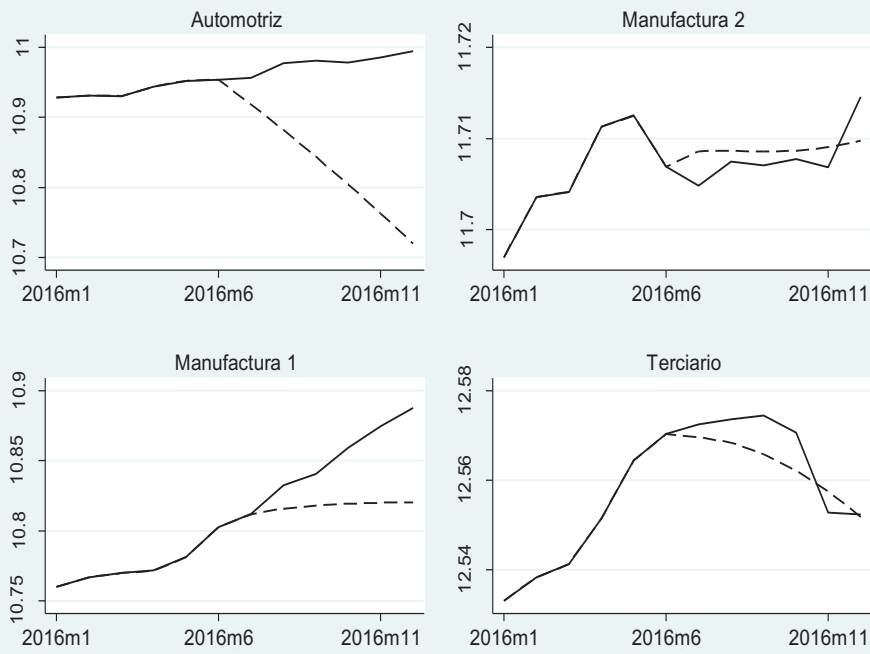
144 ECONOMÍA TeORÍA Y PRÁCTICA • Nueva Época, Número especial, vol. 4, agosto 2018

\section{Gráfica 5. Escenario 2 (Continuación)}
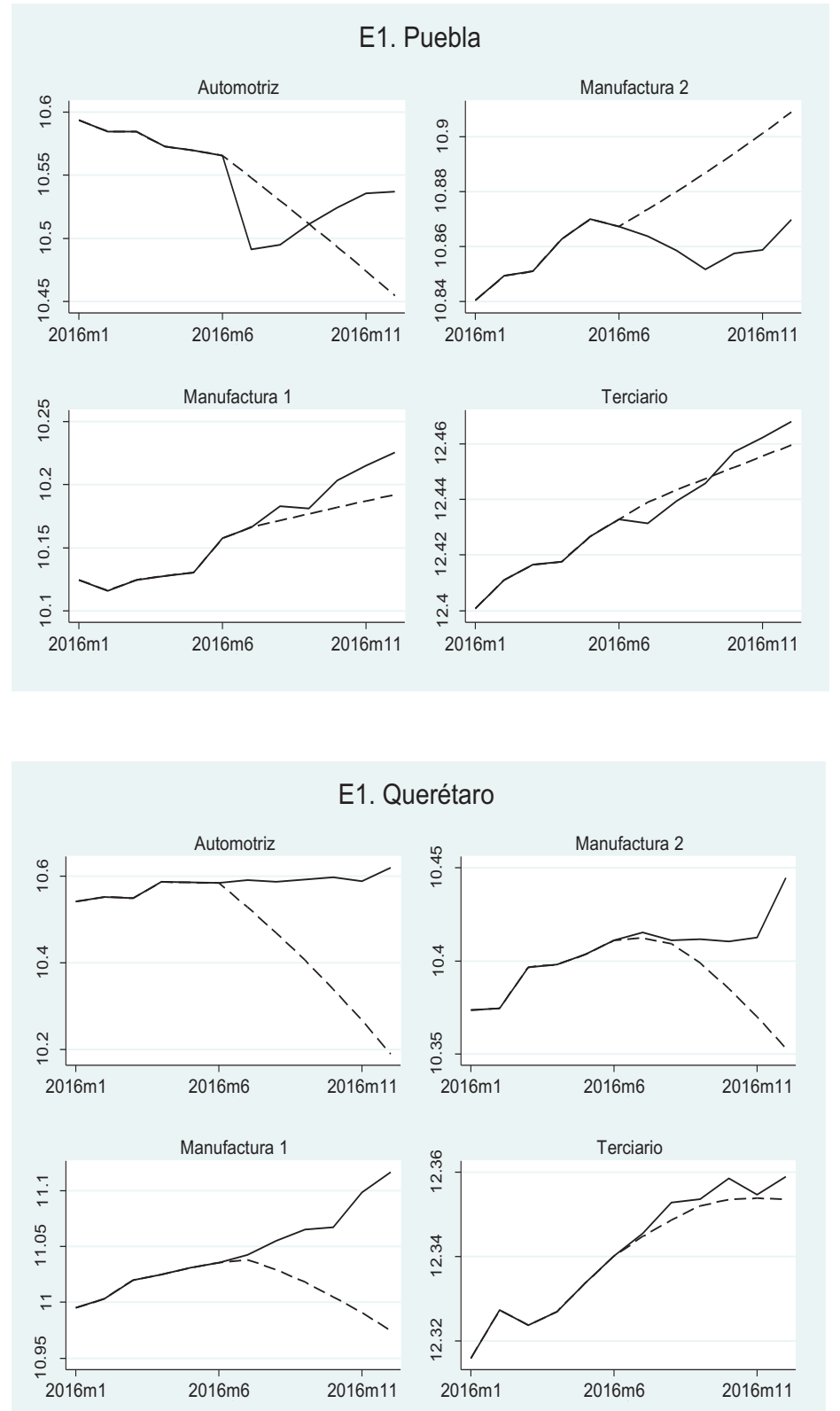

Logaritmo natural del empleo. Observado —_ Pronóstico 2 ------ 

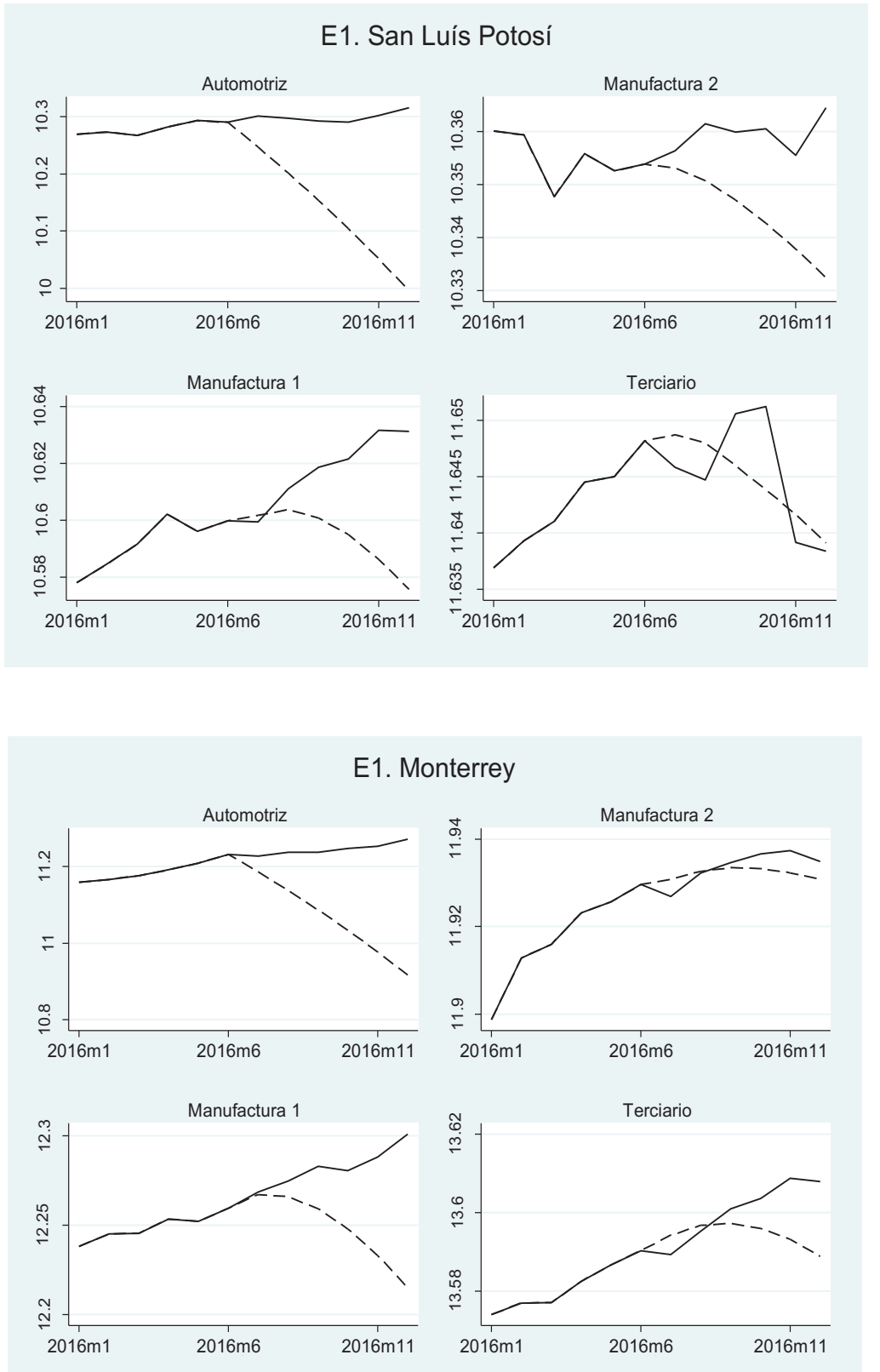
146 ECONOMÍA TeORÍA Y PRÁCTICA • Nueva Época, Número especial, vol. 4, agosto 2018

Gráfica 5. Escenario 2 (Continuación)
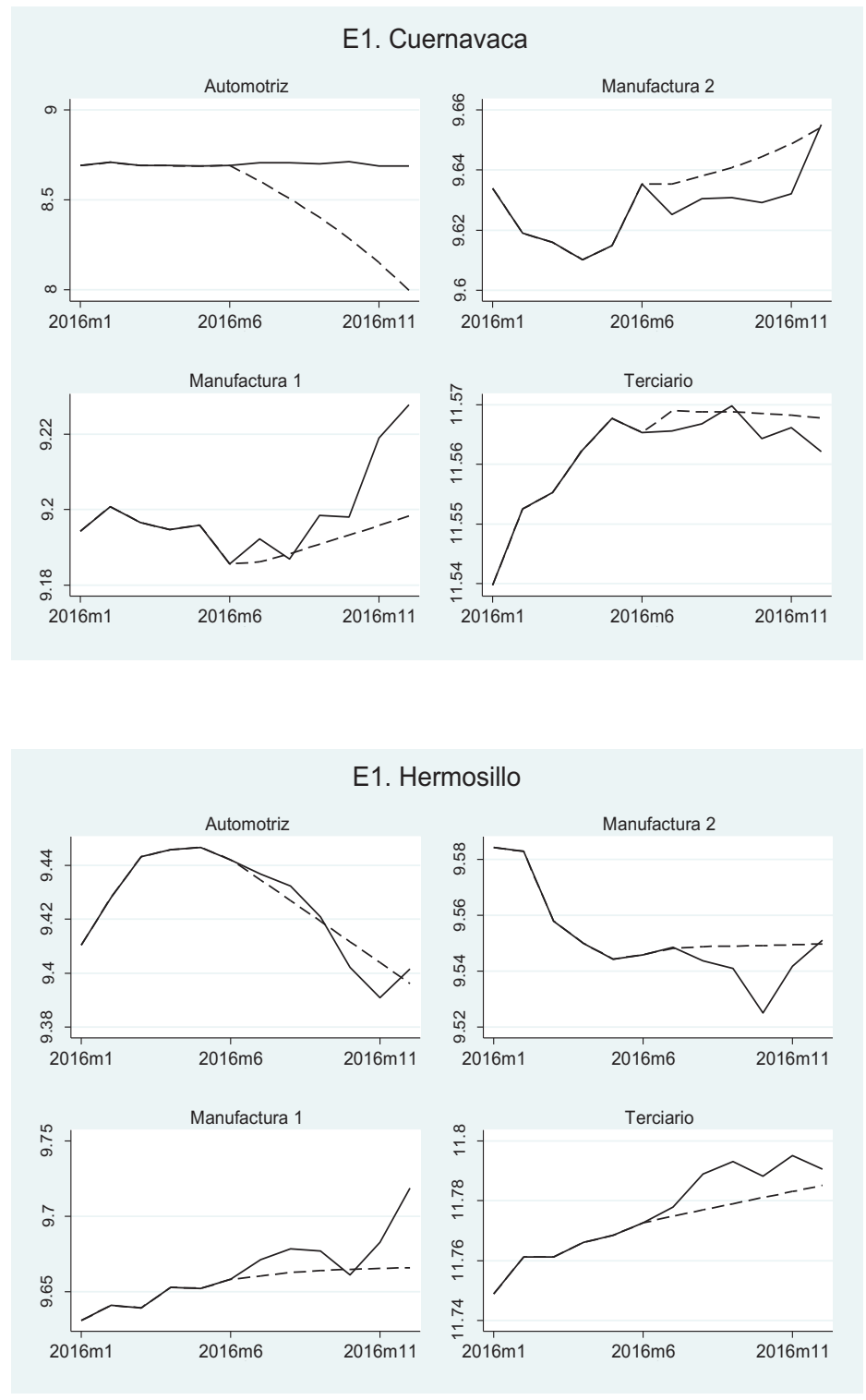

Logaritmo natural del empleo. Observado —_ Pronóstico 2 ------ 


\section{E1. Hidalgo}
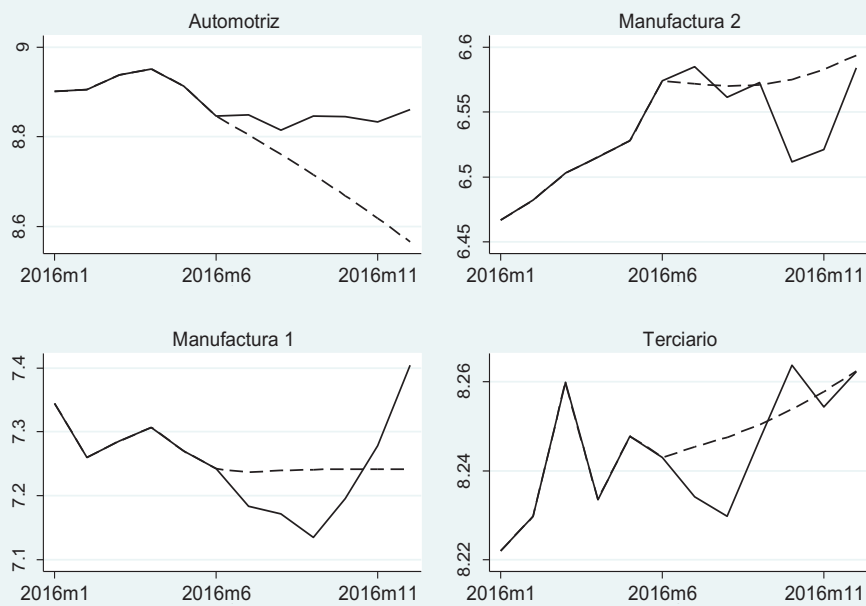

\section{E1. Chihuahua}
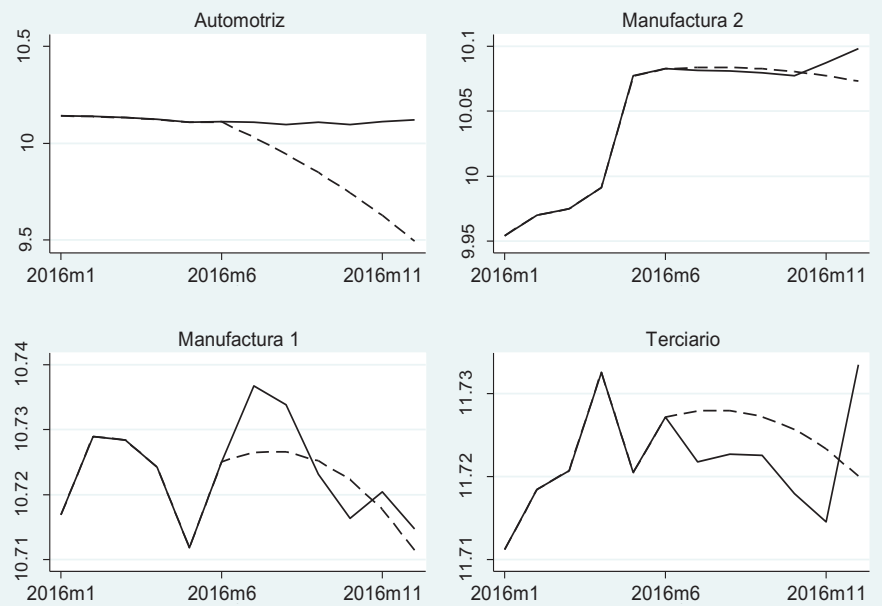
148 ECONOMÍA TeORÍA Y PRÁCTICA • Nueva Época, Número especial, vol. 4, agosto 2018

Gráfica 5. Escenario 2 (Continuación)
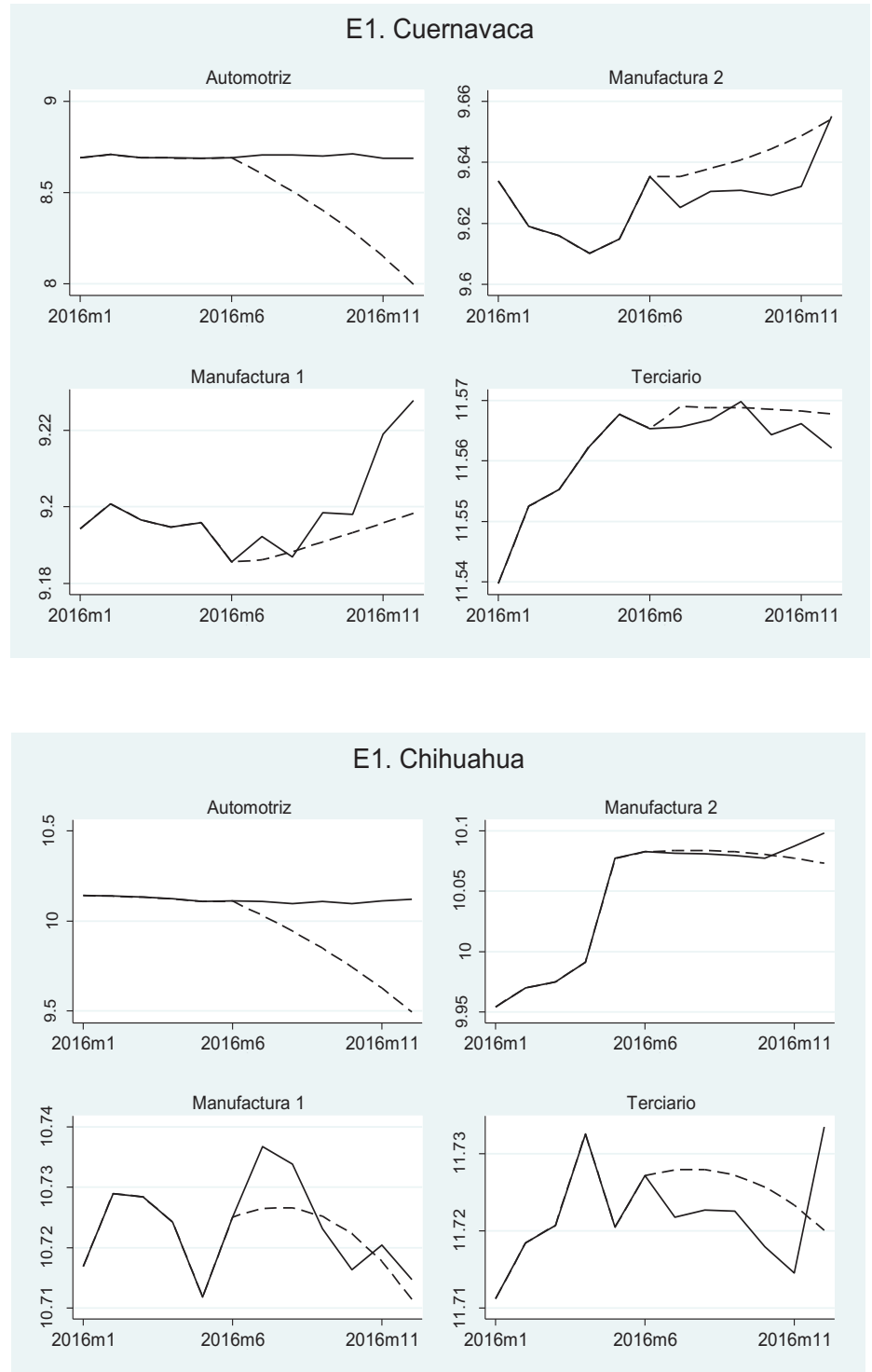

Logaritmo natural del empleo. Observado ___ Pronóstico 2 ------ 


\section{E1. Tijuana-Tecate}
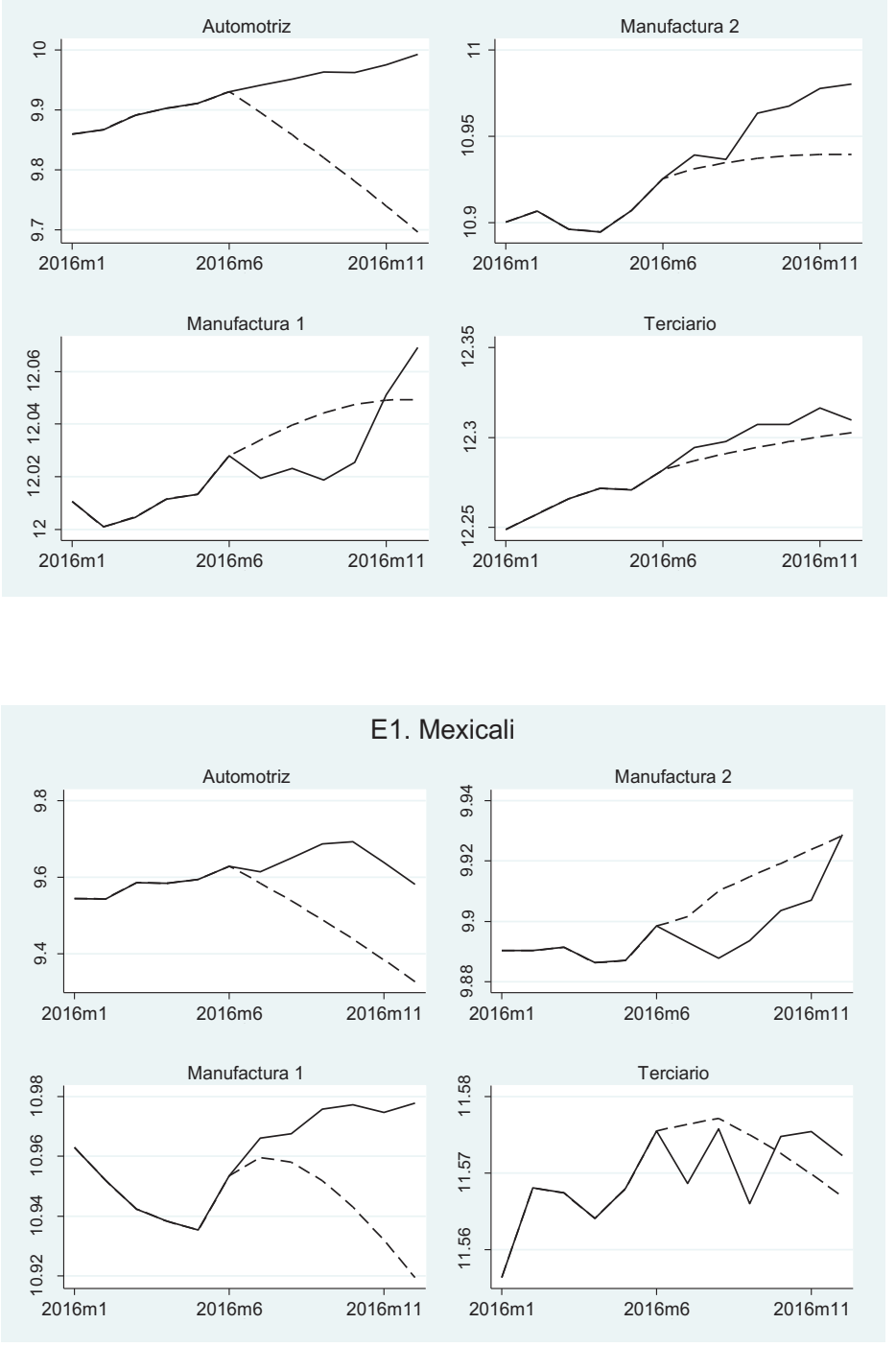


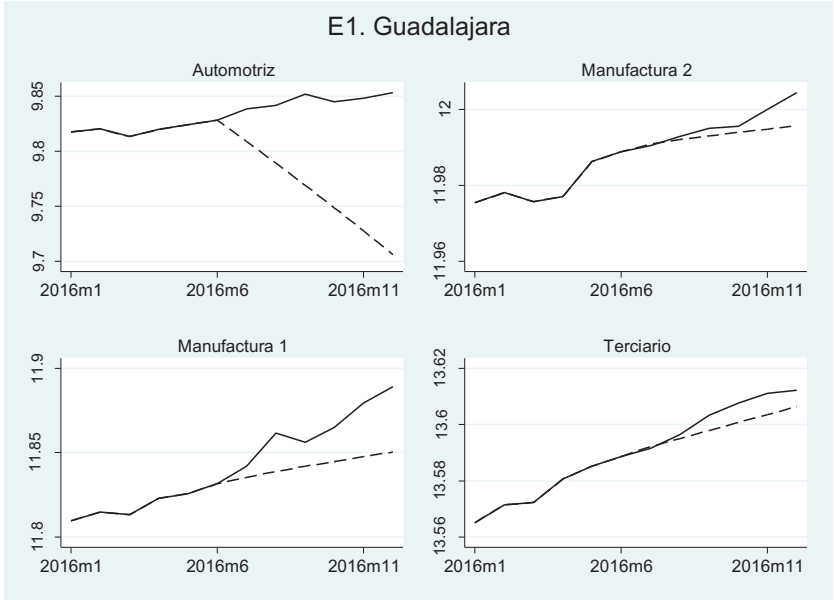

En el segundo escenario, si la reducción de empleo automotriz en cada zona fuese igual a la ocurrida durante la crisis de 2008-2009, el panorama empeoraría de manera significativa, ya que no sólo se dejarían de generar empleos, sino que éstos se reducirían en 106,592. De esa manera, el efecto total implica una pérdida de 229,068 puestos de trabajo (la reducción más los factuales). Significa que durante el semestre el empleo total decrecería en -1.83 por ciento en lugar de lograr el crecimiento factual del 2.1 por ciento. Al final del periodo, el empleo contrafactual representaría únicamente el 96.1 por ciento del factual.

El tercer escenario asume una caída igualitaria del empleo del 23.6 por ciento (el porcentaje agregado ocurrido durante la crisis). El resultado para el total de las zonas es muy parecido a la del segundo escenario, ya que se dejarían de generar 227,703 puestos laborales (los factuales más la reducción del contrafactual). Las principales diferencias entre los escenarios 2 y 3 se dan al interior de cada zona urbana, lo cual puede consultarse en los cuadros 3 y 4 .

El peor escenario es el cuarto, cuando se asume que el endurecimiento de la política comercial podría afectar directamente no sólo a la IA, sino también a otro tipo de exportaciones manufactureras, especialmente aquellas cobijadas por el programa de apoyo a la maquila y manufactura de exportación (IMMEX), cuya mayoría está incluida en la clasificación de MAN1 (además de la IA). De ahí que este escenario supone tanto el cambio exógeno en el sector automotriz como también una disminución simultánea y exógena del 12.5 por ciento del empleo en MAN1. En el agregado de las 15 zonas urbanas este escenario equivale a la pérdida de empleo en este sector durante la crisis 2008-2009. Los resultados de las proyecciones muestran 
Cuadro 3. Cambios en el empleo total bajo los distintos escenarios, segundo semestre de 2016

\begin{tabular}{|l|c|c|c|c|c|c|c|c|c|c|}
\hline \multicolumn{1}{|c|}{ ZONA } & OBSERVADO & \%* & ESC. 1 & \%* & ESC. 2 & \%* & ESC. 3 & \%* & ESC. 4 & \%* \\
\hline Aguascalientes & 4,444 & 2.0 & $-5,017$ & -2.2 & $-9,791$ & -4.4 & $-12,725$ & -5.7 & $-16,132$ & -7.2 \\
\hline Mexicali & 966 & 0.5 & $-1,875$ & -0.9 & $-6,180$ & -3.1 & $-5,498$ & -2.8 & $-12,095$ & -6.1 \\
\hline Tijuana-Tecate & 17,548 & 3.8 & 8,746 & 1.9 & 4,614 & 1.0 & 3,569 & 0.8 & $-17,012$ & -3.7 \\
\hline Saltillo-Ramos & 4,285 & 1.8 & $-8,306$ & -3.6 & $-20,098$ & -8.7 & $-22,277$ & -9.6 & $-22,600$ & -9.7 \\
\hline Chihuahua & 931 & 0.4 & $-1,976$ & -0.9 & $-13,029$ & -6.0 & $-6,082$ & -2.8 & $-11,457$ & -5.3 \\
\hline Silao-Celaya-León & 2,577 & 0.5 & $-4,672$ & -0.9 & $-16,005$ & -3.1 & $-18,881$ & -3.7 & $-24,407$ & -4.7 \\
\hline Cd. Sahagún & 434 & 3.4 & -632 & -4.9 & $-1,615$ & -12.6 & $-1,554$ & -12.1 & $-1,764$ & -13.7 \\
\hline Guadalajara & 30,141 & 2.7 & 16,439 & 1.5 & 15,816 & 1.4 & 10,613 & 1.0 & $-5,073$ & -0.5 \\
\hline Edo. de México & 7,816 & 2.2 & $-1,034$ & -0.3 & $-8,988$ & -2.5 & $-8,812$ & -2.5 & $-16,980$ & -4.8 \\
\hline Cuernavaca & 378 & 0.3 & 463 & 0.3 & $-2,307$ & -1.7 & -459 & -0.3 & $-1,346$ & -1.0 \\
\hline Monterrey & 26,874 & 2.2 & 3,069 & 0.2 & $-30,620$ & -2.5 & $-23,711$ & -1.9 & $-53,145$ & -4.3 \\
\hline Puebla & 9,822 & 2.7 & 6,063 & 1.6 & 5,843 & 1.6 & 44 & 0.0 & $-4,925$ & -1.3 \\
\hline Querétaro & 12,101 & 3.3 & 677 & 0.2 & $-15,320$ & -4.2 & $-8,820$ & -2.4 & $-16,828$ & -4.6 \\
\hline San Luis Potosí & 1,260 & 0.6 & $-3,660$ & -1.7 & $-10,159$ & -4.7 & $-9,351$ & -4.3 & $-14,637$ & -6.8 \\
\hline Hermosillo & 2,900 & 1.7 & 519 & 0.3 & 1,249 & 0.7 & $-1,282$ & -0.7 & $-3,318$ & -1.9 \\
\hline Total & 122,476 & 2.10 & 8,805 & 0.15 & $-106,592$ & -1.83 & $-105,227$ & -1.81 & $-221,719$ & -3.81 \\
\hline
\end{tabular}

*Porcentaje calculado al final del periodo con respecto del nivel observado en julio de 2016.

Fuente: elaboración propia con base en estadísticas de empleo del Imss.

que durante el segundo semestre disminuirían 221,719 empleos que, junto con los 122,476 que se hubiesen generado sin ningún cambio exógeno, arrojan un total de 344,191 puestos de trabajo. Durante ese semestre el empleo factual creció 2.1 por ciento, mientras que el contrafactual decreció -3.81 por ciento. Asimismo, el cuadro 4 muestra que, bajo este escenario, el contrafactual representaría el 94.2 por ciento del empleo factual.

En el interior de cada zona urbana, la profundidad del impacto total está determinada de manera casi directa por el grado de dependencia del empleo hacia la IA. De ahí que las más afectadas sean Hidalgo (Ciudad Sahagún y área de influencia), con pérdidas contrafactuales en los escenarios 2 y 4 del 15.4 y 16.5 por ciento (cuadro 4); Saltillo, con pérdidas contrafactuales del 10.3 y 11.4 por ciento para los mismos escenarios; y así sucesivamente: Querétaro (7.3 y 7.6 por ciento), San Luis Potosí (5.3 y 7.3 por ciento), las zonas del Estado de México, con 4.7 y 6.9 por ciento, Chihuahua (6.4 y 5.7 por ciento), Monterrey (4.6 y 6.3 por ciento) y Guanajuato (3.6 y 5.2 por ciento). Los resultados contrafactuales para cada sector y zona pueden consultarse en los cuadros A1-A4 del apéndice. 
152 ECONOMÍA TeOría y PrÁCTICA • Nueva Época, Número especial, vol. 4, agosto 2018

Cuadro 4. Empleo total a diciembre de 2016 bajo los distintos escenarios

\begin{tabular}{|l|c|c|c|c|c|c|c|c|c|}
\hline \multicolumn{1}{|c|}{ ZONA } & OBSERVADO & ESC. 1 & \%* & ESC. 2 & $\%^{*}$ & ESC. 3 & $\%^{*}$ & ESC. 4 & $\%^{*}$ \\
\hline Aguascalientes & 229,478 & 220,016 & 95.9 & 215,243 & 93.8 & 212,308 & 92.5 & 208,902 & 91.0 \\
\hline Mexicali & 199,681 & 196,841 & 98.6 & 192,536 & 96.4 & 193,218 & 96.8 & 186,621 & 93.5 \\
\hline Tijuana-Tecate & 476,842 & 468,040 & 98.2 & 463,908 & 97.3 & 462,863 & 97.1 & 442,283 & 92.8 \\
\hline Saltillo-Ramos & 236,558 & 223,967 & 94.7 & 212,175 & 89.7 & 209,996 & 88.8 & 209,673 & 88.6 \\
\hline Chihuahua & 218,812 & 215,905 & 98.7 & 204,852 & 93.6 & 211,799 & 96.8 & 206,424 & 94.3 \\
\hline Silao-Celaya-León & 518,209 & 510,960 & 98.6 & 499,627 & 96.4 & 496,751 & 95.9 & 491,224 & 94.8 \\
\hline Cd. Sahagún & 13,297 & 12,231 & 92.0 & 11,248 & 84.6 & 11,309 & 85.1 & 11,099 & 83.5 \\
\hline Guadalajara & $1,144,257$ & $1,130,555$ & 98.8 & $1,129,932$ & 98.7 & $1,124,729$ & 98.3 & $1,109,043$ & 96.9 \\
\hline Edo. de México & 360,584 & 351,734 & 97.5 & 343,780 & 95.3 & 343,956 & 95.4 & 335,788 & 93.1 \\
\hline Cuernavaca & 136,762 & 136,847 & 100.1 & 134,077 & 98.0 & 135,925 & 99.4 & 135,037 & 98.7 \\
\hline Monterrey & $1,263,452$ & $1,239,648$ & 98.1 & $1,205,958$ & 95.4 & $1,212,867$ & 96.0 & $1,183,433$ & 93.7 \\
\hline Puebla & 377,725 & 373,966 & 99.0 & 373,746 & 98.9 & 367,947 & 97.4 & 362,977 & 96.1 \\
\hline Querétaro & 375,584 & 364,159 & 97.0 & 348,162 & 92.7 & 354,663 & 94.4 & 346,655 & 92.3 \\
\hline San Luis Potosí & 216,693 & 211,773 & 97.7 & 205,274 & 94.7 & 206,082 & 95.1 & 200,796 & 92.7 \\
\hline Hermosillo & 174,789 & 172,409 & 98.6 & 173,139 & 99.1 & 170,608 & 97.6 & 168,572 & 96.4 \\
\hline 15 zonas & $5,942,723$ & $5,829,051$ & 98.1 & $5,713,655$ & 96.1 & $5,715,020$ & 96.2 & $5,598,528$ & 94.2 \\
\hline México & $18,616,619$ & $18,502,947$ & 99.4 & $18,387,551$ & 98.8 & $18,388,915$ & 98.8 & $18,272,423$ & 98.2 \\
\hline
\end{tabular}

Fuente: elaboración propia con base en estadísticas de empleo del Imss.

* Porcentaje respecto del observado. El complemento al 100 por ciento significa la pérdida del contrafactual con respecto del factual.

\section{CONCLUSiones}

La renegociación del TLCAN en los próximos meses es un hecho ineludible. Ante ese proceso, preocupa que las declaraciones realizadas en diversos medios por el presidente Donald Trump lleguen a imponerse en el nuevo acuerdo comercial, pues éstas implicarían el endurecimiento de la política comercial referente a las importaciones manufactureras provenientes de México, especialmente de la IA.

Los efectos de una modificación en esa dirección trastocarían la operación de una industria que funciona con base en una lógica de competitividad global, en la que los sistemas de producción-distribución tienen como base la segmentación en bloques dispersos alrededor del mundo, modalidad de la cual las principales marcas automotrices aprovechan las ventajas comparativas y absolutas de los países donde se ubica cada bloque. La imposición de restricciones al funcionamiento de los 
bloques localizados en México significaría la reducción o incluso la eliminación de ventajas que podrían aminorar la competitividad de las marcas automotrices (algunas de ellas estadounidenses) que producen principalmente para el mercado de EU.

Para México las consecuencias no serían irrelevantes, toda vez que la IA es una de las que tiene mayor crecimiento en el periodo de apertura comercial, con importantes contribuciones a las exportaciones, al PIB y al empleo tanto nacional como de las regiones donde se ubica, especialmente en aquellas que muestran una elevada dependencia hacia esa actividad, regiones poco diversificadas, en las cuales los efectos de una disminución de la actividad automotriz podría tener graves consecuencias sobre el empleo.

La investigación tuvo como objetivo analizar las posibles consecuencias de un aumento en las barreras comerciales de EU a la importación automotriz proveniente de México. Para ese propósito, la disposición de series de tiempo sobre las distintas actividades económicas a nivel municipal fue posible únicamente con información sobre empleo del IMSS. Con esa información se demostró causalidad a la Granger del empleo automotriz hacia el resto de actividades económicas, especialmente hacia aquellas donde predominan los proveedores automotrices, pero también hacia otras actividades que se benefician de la derrama económica regional. Con esta base se utilizó la metodología de modelos vEC para estimar escenarios que asumen distintos niveles de reducción de la actividad automotriz.

No se sabe aún cuál sería la magnitud de un hipotético, pero probable, aumento del proteccionismo a las importaciones manufactureras mexicanas. Sin embargo, en este trabajo se plantearon cuatro escenarios que, aunque su probabilidad de ocurrencia es incierta, se basan en lo observado durante la crisis de 2008-2009. Especialmente, el segundo escenario plantea para cada zona reducciones del empleo automotriz equivalentes a los porcentajes de ese periodo. Los dos últimos escenarios, aunque son más severos, representan porcentajes realmente ocurridos en los niveles agregados de las 15 zonas analizadas, mientras que el primero, a pesar de ser el más moderado porque supone una reducción igualitaria del 10 por ciento del empleo automotriz, para la mayoría de las zonas es un porcentaje por debajo de la reducción ocurrida durante 2008-2009.

Los análisis contrafactuales sobre los escenarios planteados muestran que los efectos sobre el empleo son heterogéneos entre las regiones y que afectan con mayor amplitud a las zonas más dependientes de la IA; además, los resultados proporcionan para cada región una aproximación de magnitud sobre la pérdida de empleos en todas las actividades económicas. En el agregado, el escenario moderado implica que el empleo contrafactual de todos los sectores sería equivalente al 98.1 por ciento del empleo realmente generado. El segundo escenario, que asemeja lo ocurrido en cada zona durante la crisis, arroja que el empleo contrafactual total sería el 96.1 
por ciento del factual, mientras que en el tercero y cuarto escenario el contrafactual sería el 96.2 y 94.2 por ciento del empleo factual correspondiente. Todo esto bajo la consideración de los supuestos utilizados.

Los resultados dejan ver la necesidad de implementar políticas económicas que permitan reducir el impacto de una posible modificación en las relaciones comerciales con EU. Tales medidas pudieran ser instauradas a diferentes niveles de agregación. En el ámbito nacional, la búsqueda de una mayor diversificación de mercados permitiría reducir la dependencia con el vecino del norte, mientras que, a nivel regional, las políticas públicas deberían orientarse a lograr una estructura productiva más diversificada, especialmente en las regiones donde se tiene una fuerte presencia de la IA.

\section{REFERENCIAS BIBLIOGRÁFICAS}

Aboites, Gilberto y Castro, David (2011), "Nuevos obreros y viejas tradiciones en la zona metropolitana de Saltillo", en Cerutti, M. y Villarreal J. (coords.), Coahuila 1910-2010, Economía, Historia Económica y Empre$s a$, t. I, Gobierno del Estado de Coahuila-Universidad Autónoma de Coahuila, pp. 132-168.

Aboites, Gilberto; Castro, David; Félix, Gustavo y Gutiérrez, Luis (2013), Informe Final: Estudio socioeconómico METALSA, planta Derramadero 2013. Motivadores de la gente para permanecer o abandonar su empleo, Centro de Investigaciones Socioeconómicas (CISE), Saltillo, Coahuila, 6 de diciembre, pp. 1-140.

Aguilar, Ismael (1994), "Industrialización regional y apertura en los ochenta: el sector automotriz de Nuevo León", Investigación Económica, UNAM.

Álvarez, Lourdes; Carrillo, Jorge y González, María Luisa (coords.) (2014), El auge de la industria automotriz en México en el siglo XXI: Reestructuración y Catching Up, UNAM-FCA-IIE-El Colef, pp. 109-132.

Arévalo, José (1998), Proveedores de autopartes, tipos de relaciones y grado de integración de la producción en el sector automotriz: el caso de la región sureste de Coahuila. Tesis de Maestría en Economía Regional, Saltillo, Coahuila, Centro de Investigaciones Socioeconómicas de la Universidad Autónoma de Coahuila.

Asociación Mexicana de la Industria Automotriz A.C. (2017), Producción total, AMIA, México, http://www.amia.com.mx/prodtot.html, consultado el 20 de enero de 2017.

Automotive Meetings (2016), Industria-automotriz-en-México. Un Sector Clave, http://www.automotivemeetings.com/mexico/index.php/es/industria-automotriz-en-mexico, consultado el 20 de enero de 2017. 
Breitung, Jörg y Candelon, Bertrand (2006), "Testing for short- and long-run causality: A frequency-domain approach", Journal of Econometrics, 132, pp. 363-378.

Carbajal, Yolanda; Almonte, Leobardo y Mejía, Pablo (2016), "La manufactura y la industria automotriz en cuatro regiones de México. Un análisis de su dinámica de crecimiento, 1980-2014", Economía: Teoría y Práctica, Nueva Época, 45, pp. 39-66.

Carbajal, Yolanda y Del Moral, Laura Elena (2014), "El desempeño del sector automotriz en México en la era TLCAN. Un análisis a 20 años", Paradigma Económico, 6 (2), pp. 95-126.

Covarrubias, Alex; Sandoval, Sergio; Bensunsán, Graciela y Arteaga, Arnulfo (coords.) (2016), La industria automotriz en México, relaciones de empleo, culturas organizacionales y factores psicosociales, CIAD-Colson-Clave Editorial, pp. 179-196.

Covarrubias, Alex (2014), Explosión de la industria automotriz en México: De sus encadenamientos actuales a su potencial transformador, Documento de trabajo, 1/2014, Fundación Friedrich Ebert Stiftug-México, 44.

Dávila, Alejandro y Escamilla, Antonio (2013), “Apertura comercial, cambios en la estructura productiva y desempeño de la economía de los estados de la Frontera Norte de México: 1993-2004”, Región y Sociedad, El Colegio de Sonora, vol. XXV, núm. 56, enero-abril de 2013, pp. 9-41.

Dávila, Mario (1997), Análisis del sector exportador de Coahuila. Tesis de Maestría, Facultad de Economía de la Universidad Autónoma de Coahuila.

Durbin, Dee-Ann (2017), "Cobrar impuestos a los autos fabricados en México convulsionaría industria en EU”, Periódico Vanguardia, México, página web descargada el 29 de junio de 2017, http://www.vanguardia.com.mx/articulo/ cobrar-impuestos-los-autos-fabricados-en-mexico-convulsionaria-industria-en-eu.

Félix, Gustavo y Castro, David (2015), "Demanda laboral en las industrias integradas en cadenas de valor internacional: un análisis con panel dinámico no estacionario para el caso de México", [pdf] en International Conference of Regional Science: Innovation and geographical spillovers: new approaches and evidence, Universitat Rovira i Virgili, Reus, España.

Galicia-Bretón, Fabiola y Sánchez-Juárez, Isaac (2011), "La industria automotriz y el fomento a las cadenas productivas en Sonora: el caso de la Ford en Hermosillo", Economía, Sociedad y Territorio, XI (35), pp. 161-195.

Johansen, Soren (1988), "Statistical analysis of cointegration vectors", Journal of Economic Dynamics and Control, 12, pp. 231-254. 
(1991), "Estimation and hypothesis testing of cointegration vectors in Gaussian vector autoregressive models", Econometrica, 59, pp. 1551-1580. (1995), Likelihood-Based Inference in Cointegrated Vector Autoregressive Models, Oxford, Oxford University Press.

Jones, Ronald y Kierzkowoski, Henryk (1990), "The role of services in production and international trade: A theoretical framework", en Jones, R.W. y Krueger A. (eds.), The political economy of international trade: Essays in honor of Robert E. Baldwin, Oxford, Basil Blackwell.

(2000), “A framework for fragmentation”, en Arndt, S. y Kierzkowski, H. (eds.), Fragmentation: New Production Patterns in the World Economy, Oxford University Press.

(2005), "International fragmentation and the new economic Geography", North American Journal of Economics and Finance, 16, pp. 1-10.

Kimura, Fukunari; Takahashi, Yuya y Hayakawa, Kazunobu (2007), "Fragmentation and parts and components trade: Comparison between East Asia and Europe", North American Journal of Economics and Finance, 18, pp. 23-40.

Millones, M. (2012), "Volkswagen de México: reestructuración, flexibilidad y conflictos", Revista de Estudios Transfronterizos, XII (2), pp. 19-49.

Miniam, Isaac y Brown, Flor (1997), "Las redes inter-firma de proveedores innovadores: ejemplos en la industria de autopartes mexicana", en Lara y Velázquez (comps.), México y Estados Unidos, el reto de la interdependencia económica, El Colegio de Sonora.

ProMéxico (2016), La industria automotriz mexicana: Situación actual, retos y oportunidades, SE, http://www.promexico.mx/documentos/biblioteca/la-industria-automotriz-mexicana.pdf, 27/06/2017.

Ruiz, Clemente (1998), "Redes industriales: organización fundamental de la economía globalizada", El Mercado de Valores, Esquemas de organización industrial, 98, 2.

(2015), Crisis y rediseño del capitalismo en el siglo XXI, Universidad Autónoma de Baja California-Miguel Ángel Porrúa, serie Economía, Finanzas y Administración, pp. 1-186.

Secretaría de Economía (2012), Industria Automotriz Monografía. México, [pdf] marzo, http://www.economia.gob.mx/files/comunidad_negocios/industria comercio/Monografia_Industria_Automotriz_MARzo_2012.pdf, 27/06/2017. 
Sistema de Información Empresarial Mexicano (2017), Cadenas productivas del sector automotriz, https://www.siem.gob.mx/siem/portal/cadenas/CadenasProductivas.asp, 27/06/2017.

Sturgeon, Timothy y Florida, Richard (2000), "Globalization and Jobs in the Automotive Industry", [pdf] Cambridge, Industrial Performance Center/Massachusetts, Institute of Technology, https://ipc.mit.edu/sites/default/files/documents/00-012.pdf, 2/2/2017.

Tastan, Hüseyin (2015), "Testing for spectral Granger causality", The Stata Journal 15 (4), pp. 1157-1166.

Valdés, Miriam (2008), Cluster automotriz en México. Un análisis de eficiencia económica y sus determinantes: 1988-2003. Tesis de Maestría en Economía Regional, Saltillo, Coahuila, Centro de Investigaciones Socioeconómicas de la Universidad Autónoma de Coahuila. 
158 ECONOMÍA TeORÍA y PRÁCTICA • Nueva Época, Número especial, vol. 4, agosto 2018

\section{ApÉNDICE}

Gráfica A1. Prueba Breitung-Candelon para causalidad espectral a la Granger

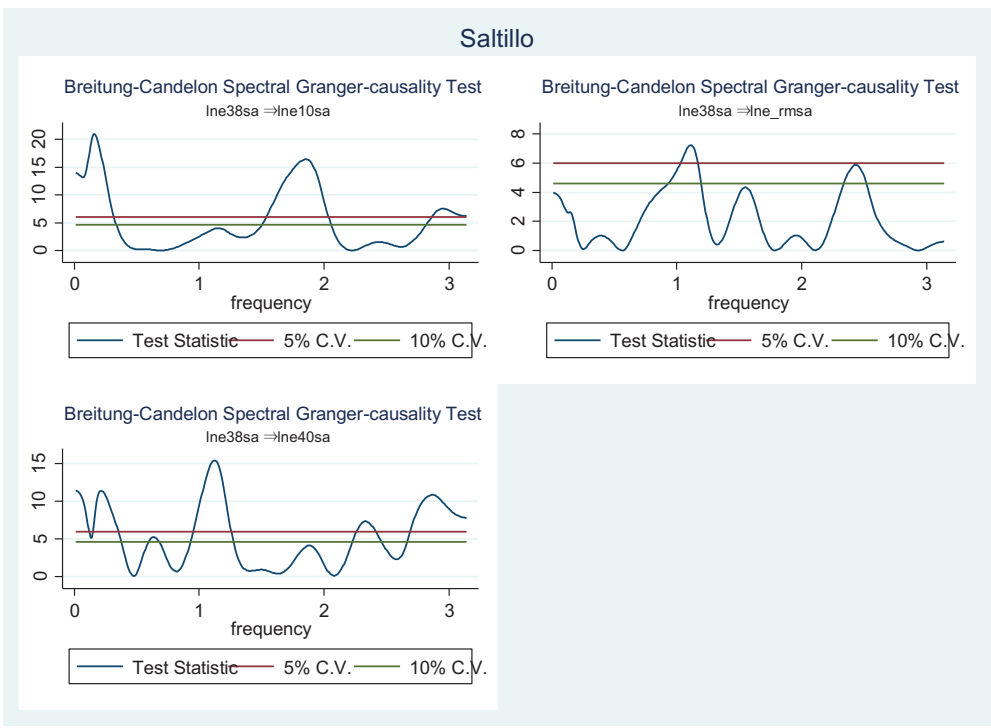

Aguascalientes

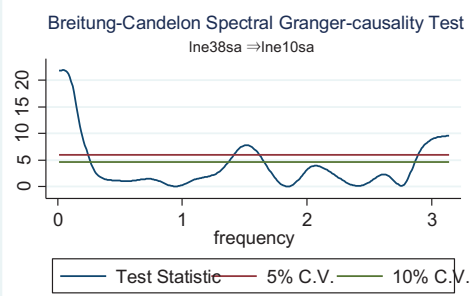

Breitung-Candelon Spectral Granger-causality Test

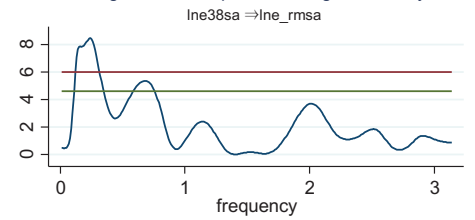

Breitung-Candelon Spectral Granger-causality Test

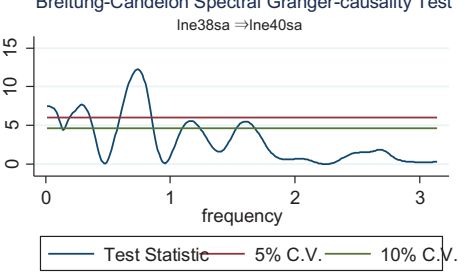




\section{Zonas del Estado de México}

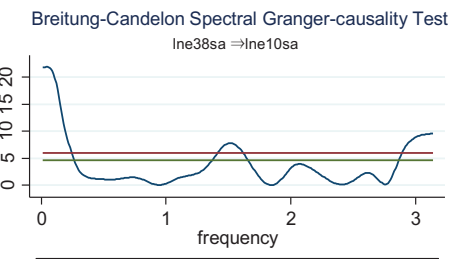

Breitung-Candelon Spectral Granger-causality Test

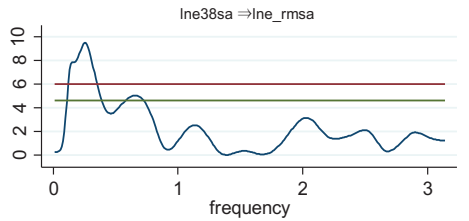

- Test Statistie- 5\% C.V.— 10\% C.V

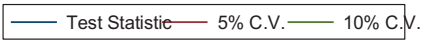

Breitung-Candelon Spectral Granger-causality Test Ine38sa $\Rightarrow$ Ine40sa

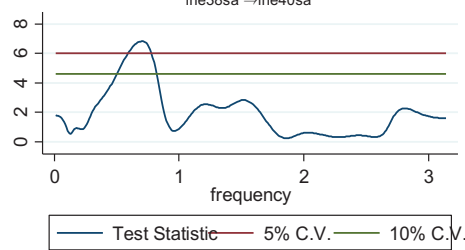

\section{Irapuato-Celaya-León}

Breitung-Candelon Spectral Granger-causality Test Ine38sa $\Rightarrow$ Ine10sa

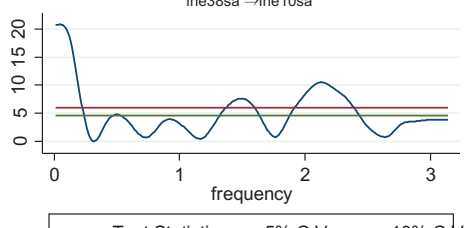

Test Statistie $\quad 5 \%$ C.V.— 10\% C.V.

Breitung-Candelon Spectral Granger-causality Test Ine38sa $\Rightarrow$ Ine40sa

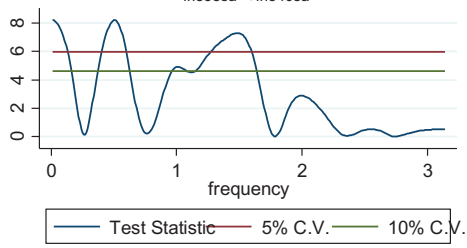

Breitung-Candelon Spectral Granger-causality Test Ine38sa $\Rightarrow$ Ine rmsa

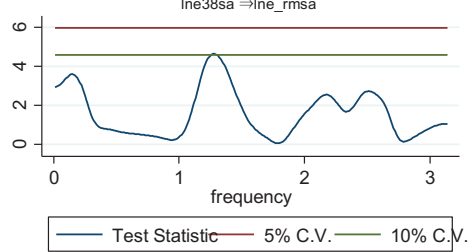


160 ECONOMÍA TeOrÍA Y PrÁCTICA • Nueva Época, Número especial, vol. 4, agosto 2018

\section{Gráfica A1. (Continuación)}

\section{Puebla}

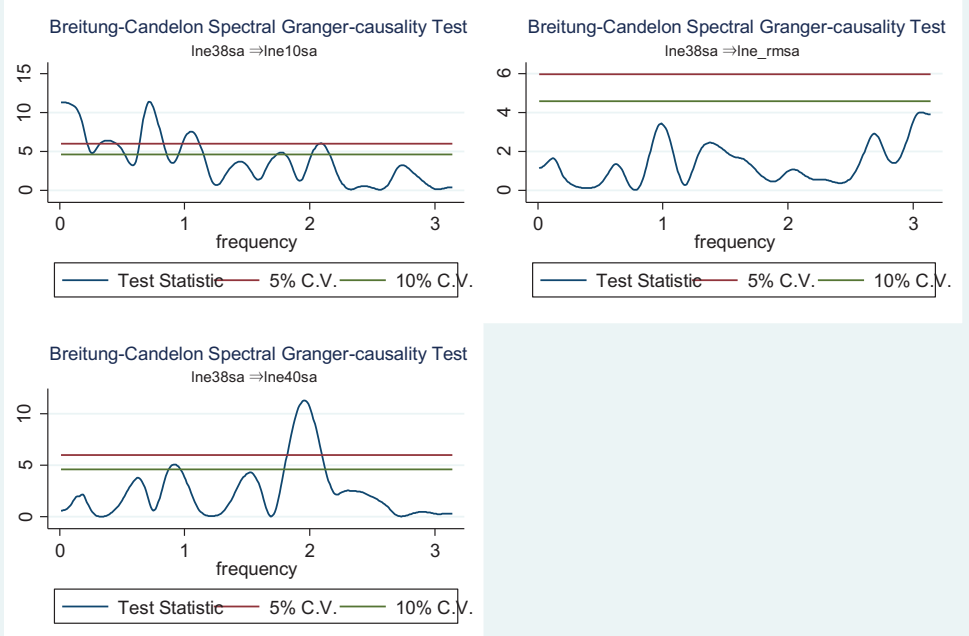

\section{Querétaro}

Breitung-Candelon Spectral Granger-causality Test Ine38sa $\Rightarrow$ Ine10sa

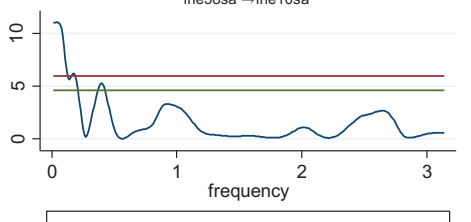

Breitung-Candelon Spectral Granger-causality Test

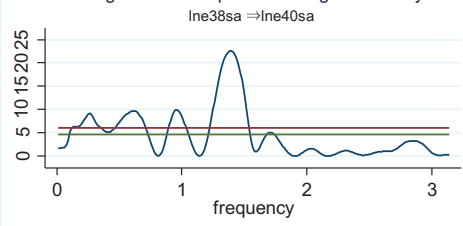

Test Statistie $5 \%$ C.V. $-10 \%$ C.V.
Breitung-Candelon Spectral Granger-causality Test Ine38sa $\Rightarrow$ Ine rmsa

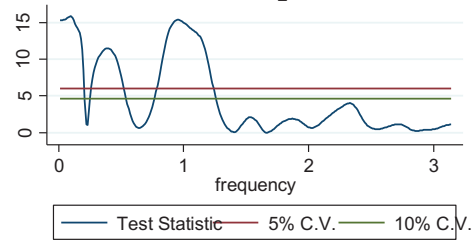




\section{san LuIS rotos}
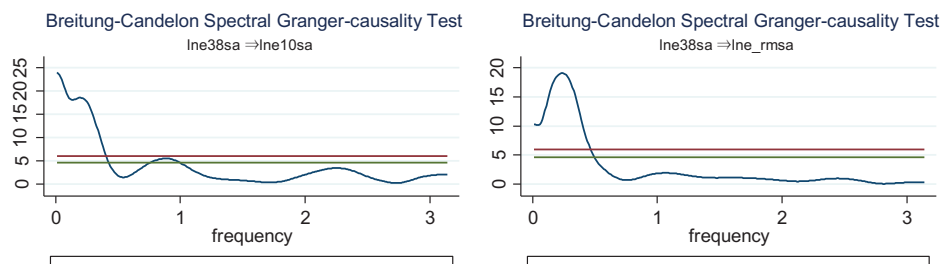

Breitung-Candelon Spectral Granger-causality Test

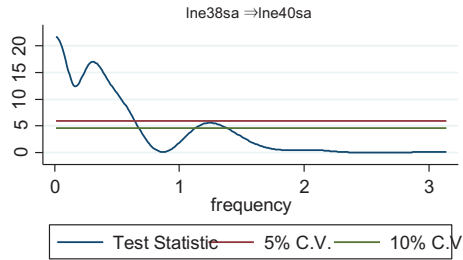

IVıonterrey

Breitung-Candelon Spectral Granger-causality Test

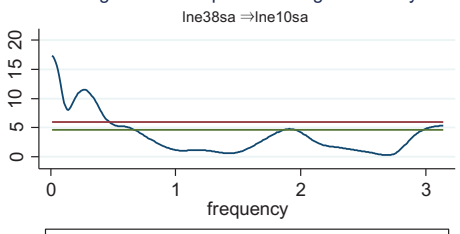

- Test Statistie $\quad 5 \%$ C.V.— $10 \%$ C.N.

Breitung-Candelon Spectral Granger-causality Test iิ-

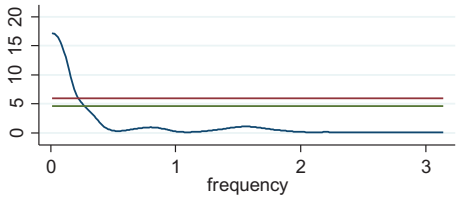

- Test Statistie - 5\% C.V.— 10\% C.N.
Breitung-Candelon Spectral Granger-causality Test Ine38sa $\Rightarrow$ Ine_rmsa

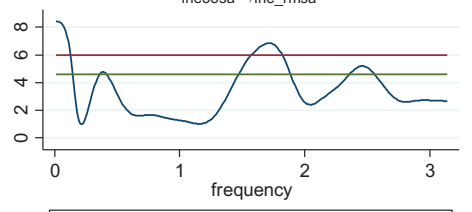

- Test Statistie - 5\% C.V.— 10\% C.V 
162 ECONOMÍA TeOrÍA y PrÁCTICA • Nueva Época, Número especial, vol. 4, agosto 2018

\section{Gráfica A1. (Continuación)}

\section{Hidalgo}

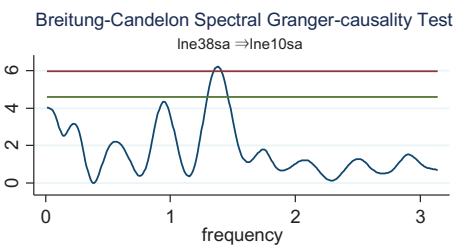

Breitung-Candelon Spectral Granger-causality Test

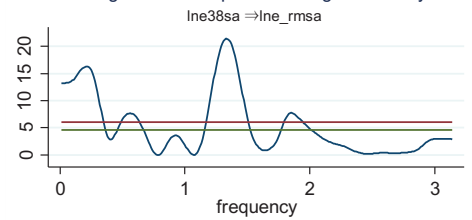

- Test Statistie $5 \%$ C.V. $-10 \%$ C.V.

Test Statistie $5 \%$ C.V. $10 \%$ C.N.

Breitung-Candelon Spectral Granger-causality Test Ine38sa $\Rightarrow$ Ine 40 sa

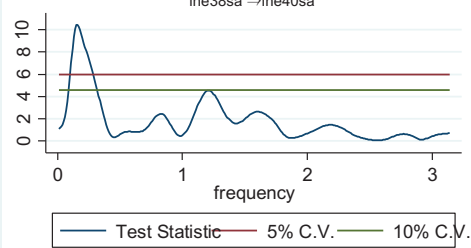

\section{Hermosillo}

Breitung-Candelon Spectral Granger-causality Test Ine38sa $\Rightarrow$ Ine10sa

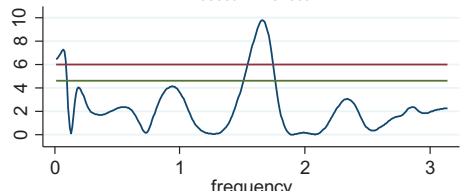

frequency

Test Statistie- $5 \%$ C.V. $10 \%$ C.V.

Breitung-Candelon Spectral Granger-causality Test Ine38sa $\Rightarrow$ Ine40sa

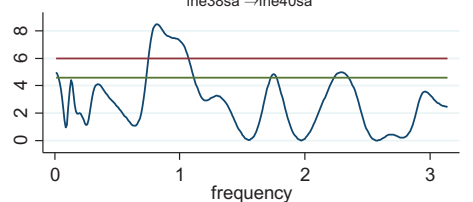

- Test Statistie - 5\% C.V.— 10\% C.N.
Breitung-Candelon Spectral Granger-causality Test Ine38sa $\Rightarrow$ Ine_rmsa

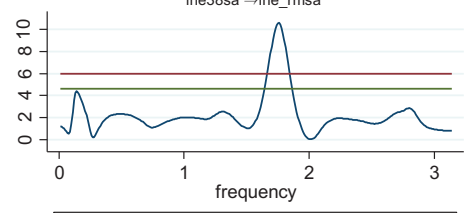

Test Statistie- 5\% C.V.— 10\% C.V. 


\section{Cuernavaca}

Breitung-Candelon Spectral Granger-causality Test Ine38sa $\Rightarrow$ Ine 10 sa

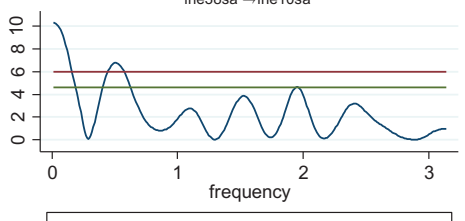

Test Statistie- 5\% C.V.— 10\% C.V.

Breitung-Candelon Spectral Granger-causality Test Ine38sa $\Rightarrow$ Ine40sa

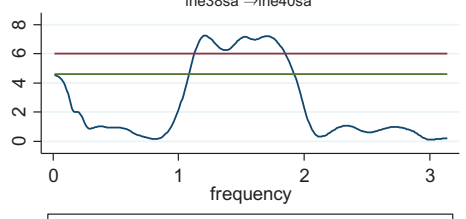

Test Statistie $-5 \%$ C.V.- $10 \%$ C.N.
Breitung-Candelon Spectral Granger-causality Test Ine38sa $\Rightarrow$ Ine_rmsa

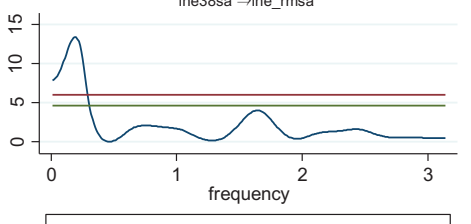

\section{Chihuahua}

Breitung-Candelon Spectral Granger-causality Test Ine38sa $\Rightarrow$ Ine10sa

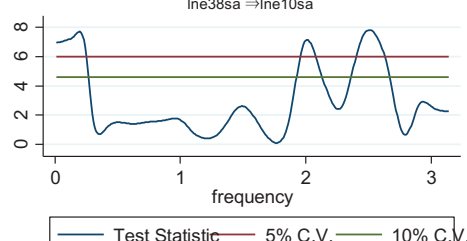

Breitung-Candelon Spectral Granger-causality Test Ine38sa $\Rightarrow$ Ine40sa

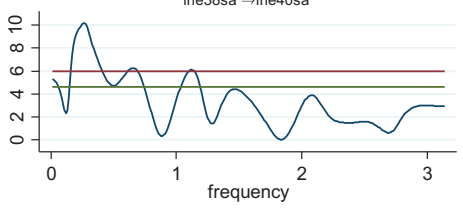

Test Statistie- 5\% C.V.— 10\% C.V.
Breitung-Candelon Spectral Granger-causality Test Ine38sa $\Rightarrow$ Ine_rmsa

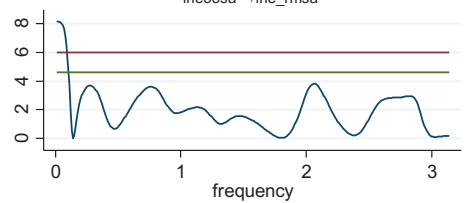

- Test Statistie — 5\% C.V.—— 10\% C.V. 
164 ECONOMÍA TeOrÍA y PrÁCTICA • Nueva Época, Número especial, vol. 4, agosto 2018

\section{Gráfica A1. (Continuación)}

\section{Tijuana-Tecate}
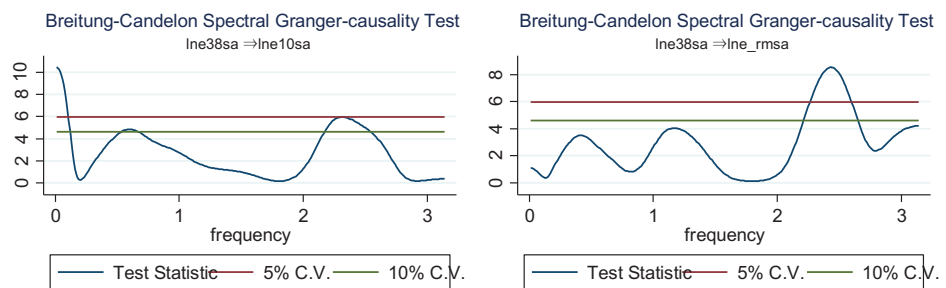

Breitung-Candelon Spectral Granger-causality Test Ine38sa $\Rightarrow$ Ine40sa

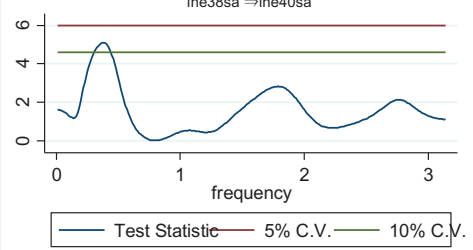

\section{Mexicali}

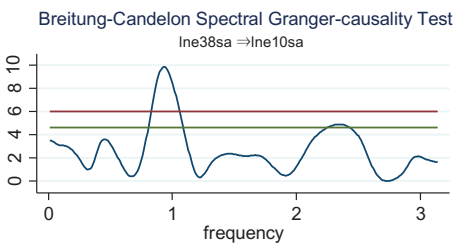

Breitung-Candelon Spectral Granger-causality Test

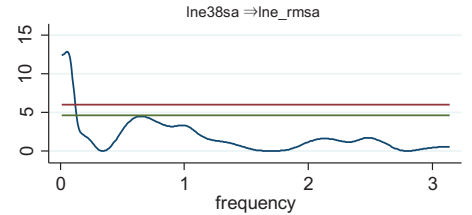

- Test Statistie $5 \%$ C.V.— 10\% C.V.

Test Statistie $5 \%$ C.V.— 10\% C.V.

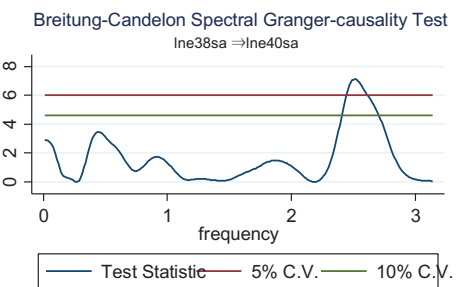




\section{Guadalajara}

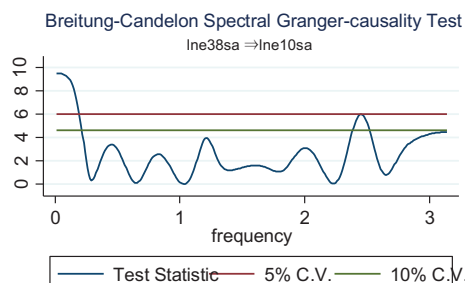

Breitung-Candelon Spectral Granger-causality Test

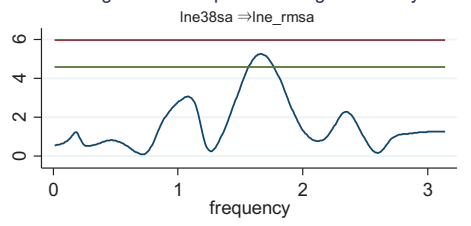

- Test Statistie $5 \%$ C.V.— $10 \%$ C.V.

Breitung-Candelon Spectral Granger-causality Test Ine38sa $\Rightarrow$ Ine40sa

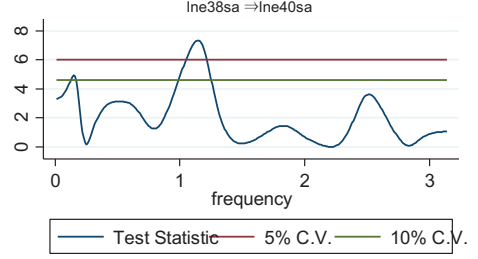

Notas: logaritmo del empleo en: Auto (Ine38sa); Man1 (Ine40sa); Man2 (Ine_rmsa); Terciario (Ine10sa). Interpretación: Para los tramos de la curva (test statics) que pasan por encima de la línea del 5 por ciento (línea horizontal superior), la causalidad a la Granger es significativa a ese porcentaje o menor. Las frecuencias convertidas a periodos mensuales se obtienen utilizando la expresión $\frac{2 \pi}{\omega}$, donde $\omega$ es la frecuencia en el intervalo $(0, \pi)$. Como ejemplo, para la primera gráfica de Saltillo, la causalidad del empleo automotriz hacia el sector terciario se da en los tramos de la curva que están por encima de la línea del 5 por ciento, es decir, en las frecuencias $(0,0.31),(1.61,2.03)$ y $(2.86, \pi)$, las cuales significan periodos de corto plazo menores a cuatro meses y de largo plazo mayores a 20 meses. Para esta prueba se siguió el procedimiento de STATA desarrollado por Tastan (2015).2 
166 ECONOMÍA TeORÍA Y PRÁCTICA • Nueva Época, Número especial, vol. 4, agosto 2018

\section{Gráfica A2. Prueba Breitung-Candelon para causalidad espectral a la Granger}
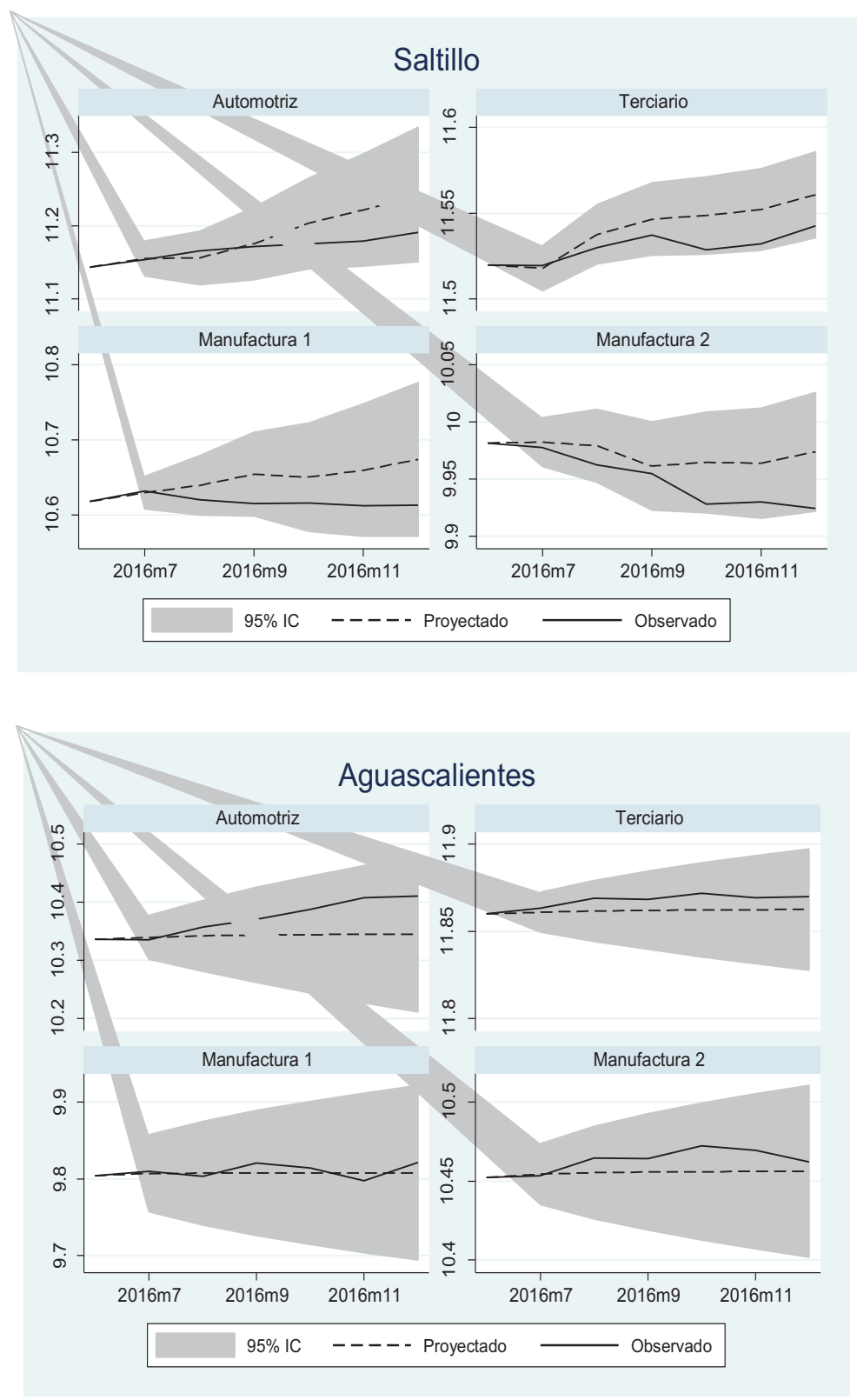

Logaritmo natural del empleo. Observado ___ Pronóstico ------ 

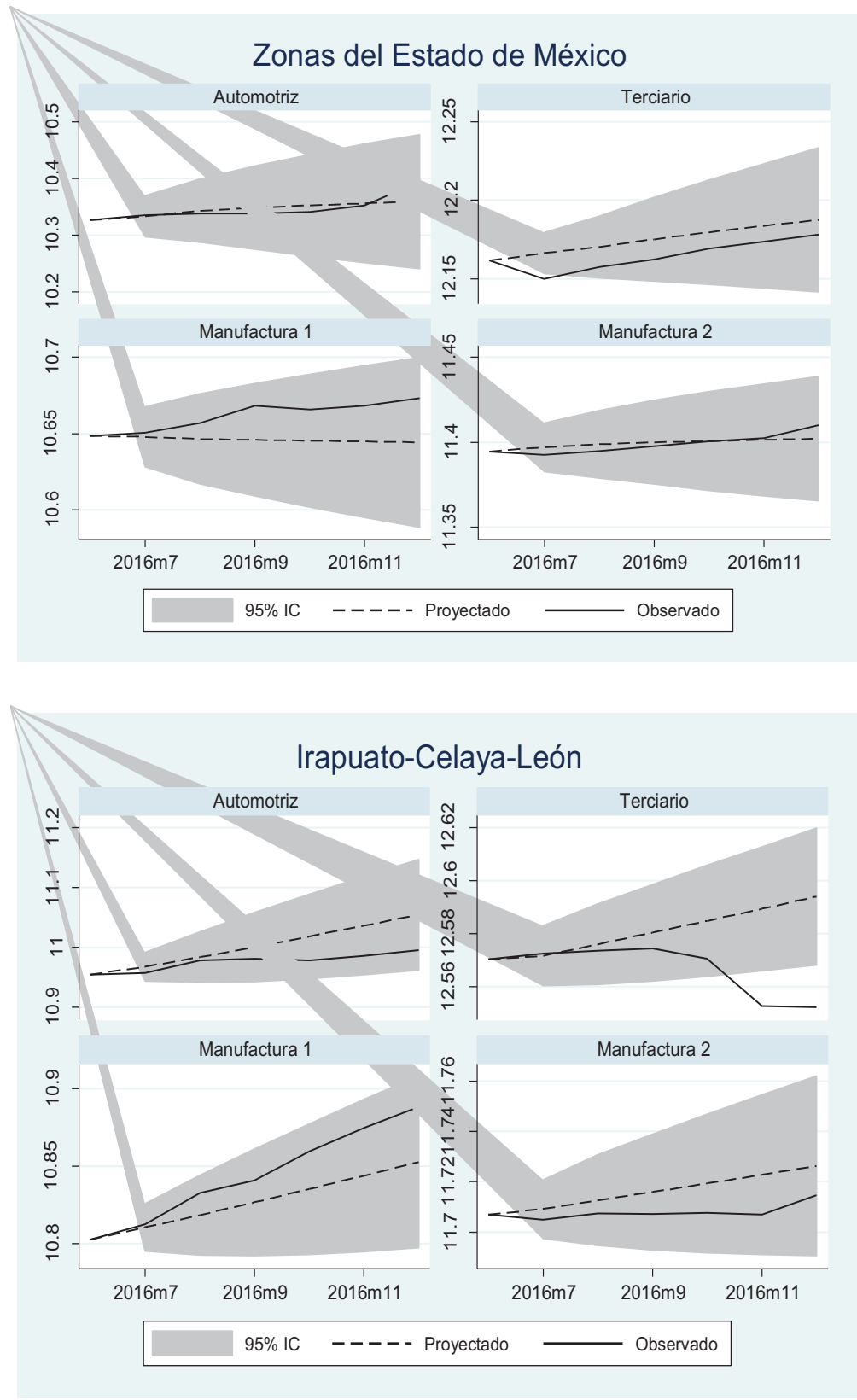


\section{Gráfica A2. (Continuación)}
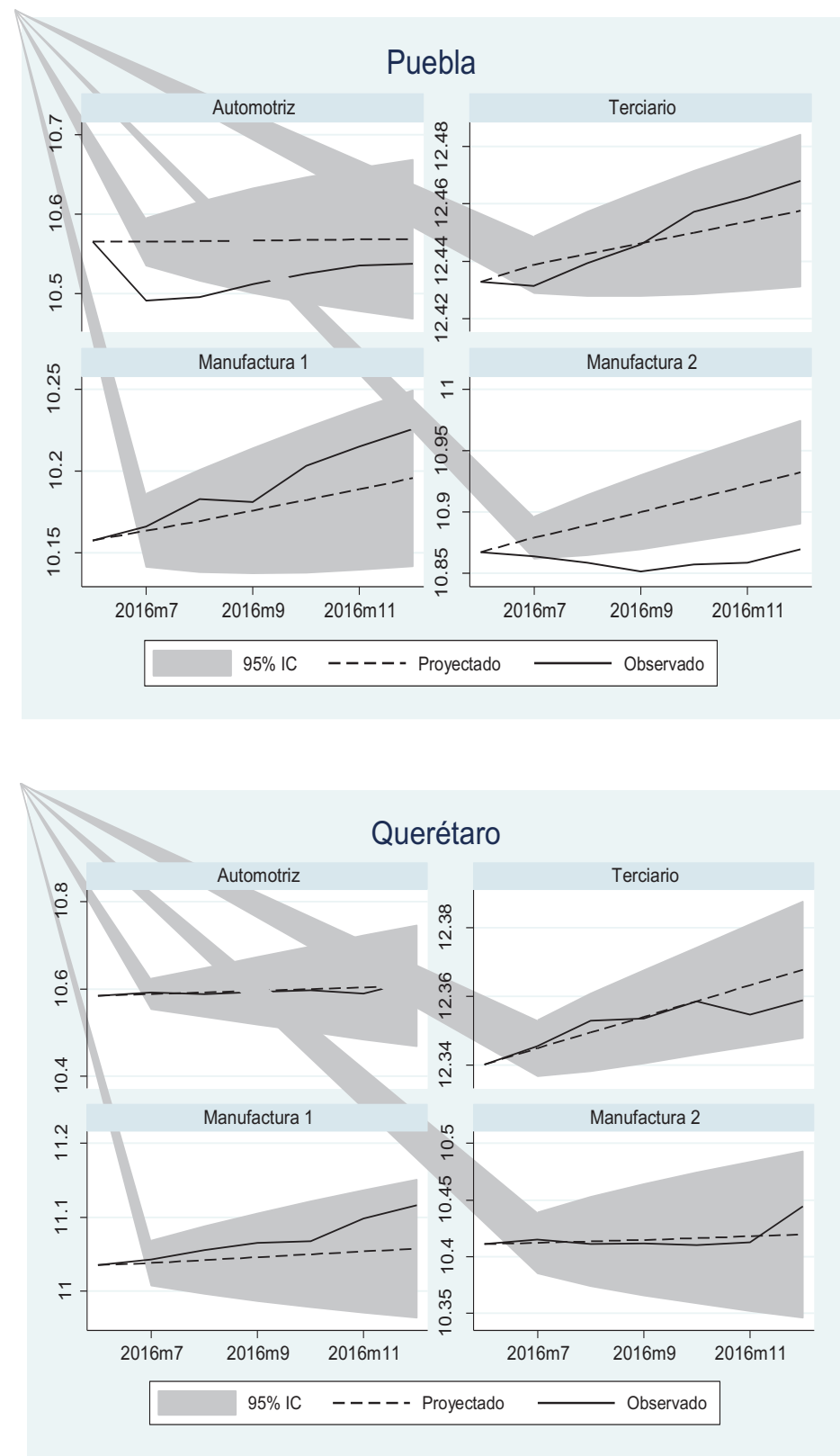

Logaritmo natural del empleo. Observado —_ Pronóstico ------ 

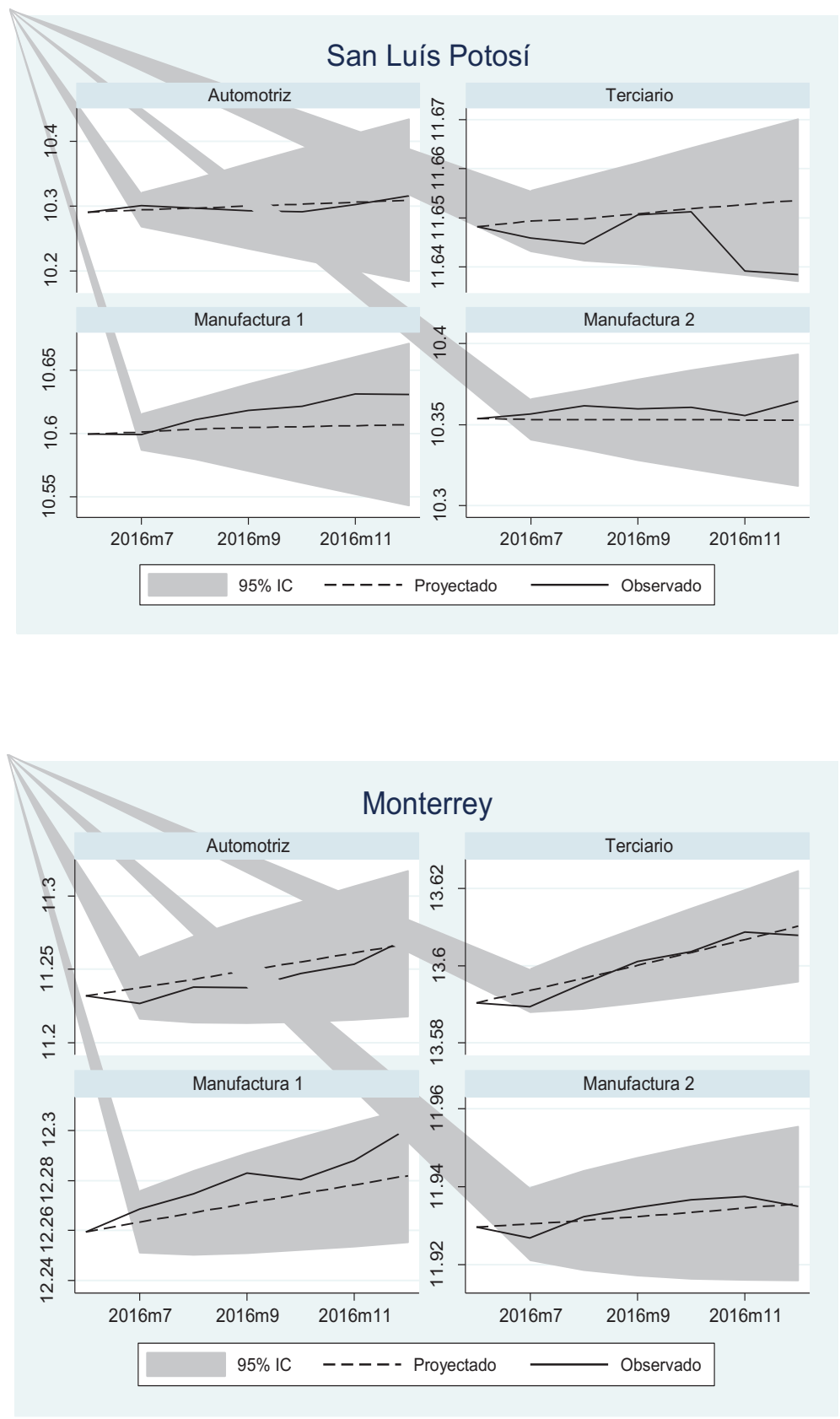
170 ECONOMÍA TeORÍA Y PRÁCTICA • Nueva Época, Número especial, vol. 4, agosto 2018

\section{Gráfica A2. (Continuación)}
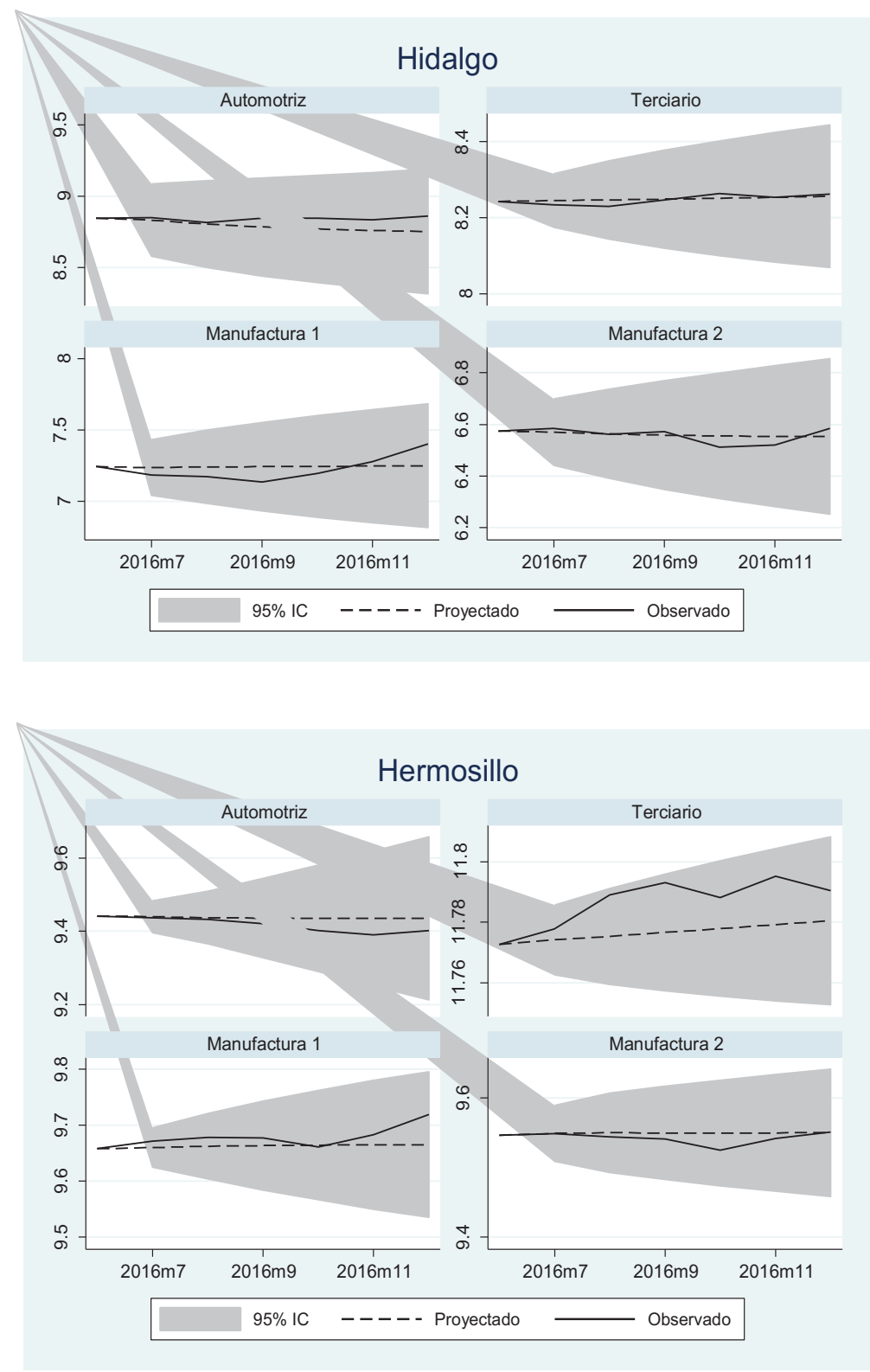

Logaritmo natural del empleo. Observado —— Pronóstico ------ 

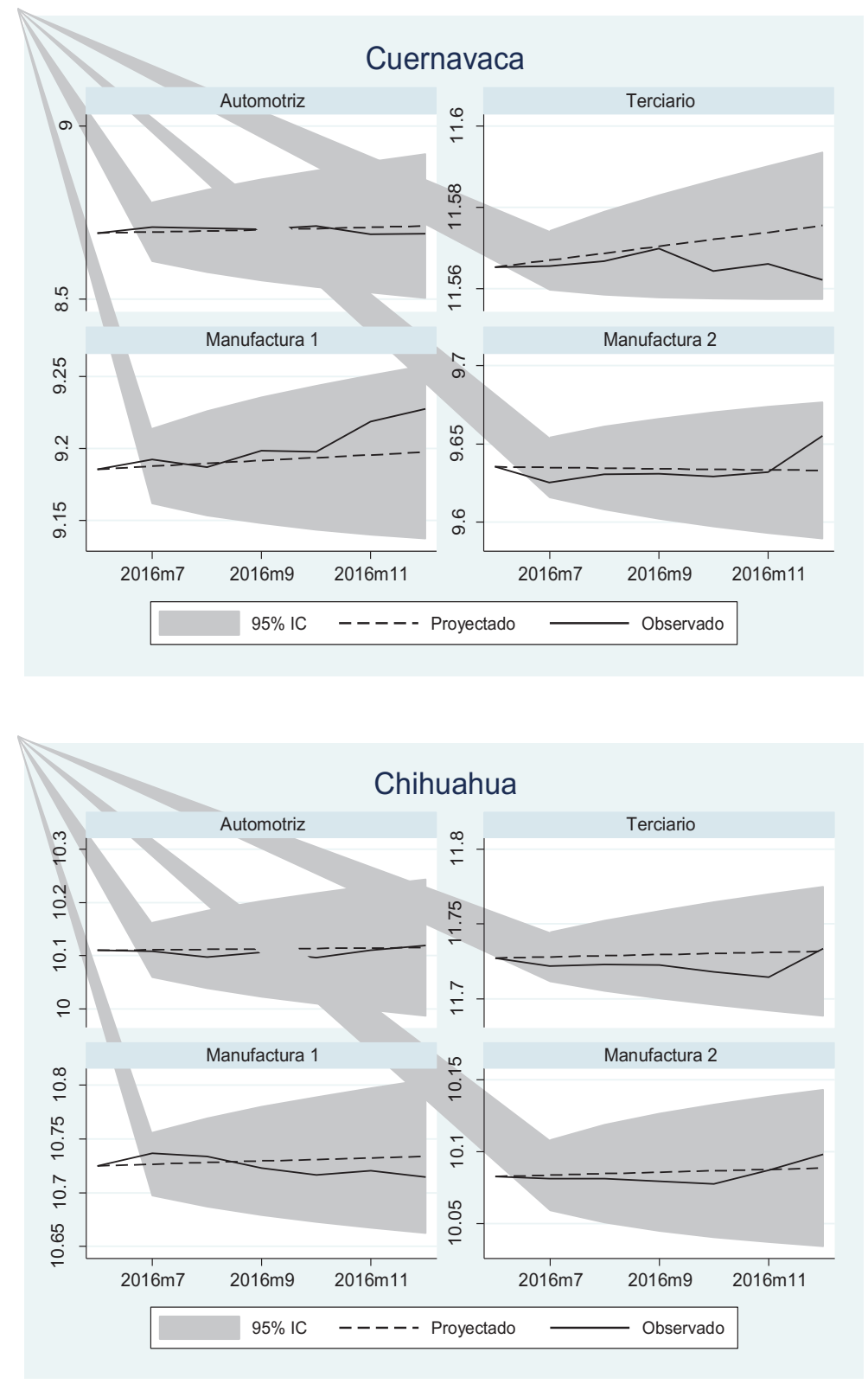
172 ECONOMÍA TeORÍA Y PRÁCTICA • Nueva Época, Número especial, vol. 4, agosto 2018

\section{Gráfica A2. (Continuación)}
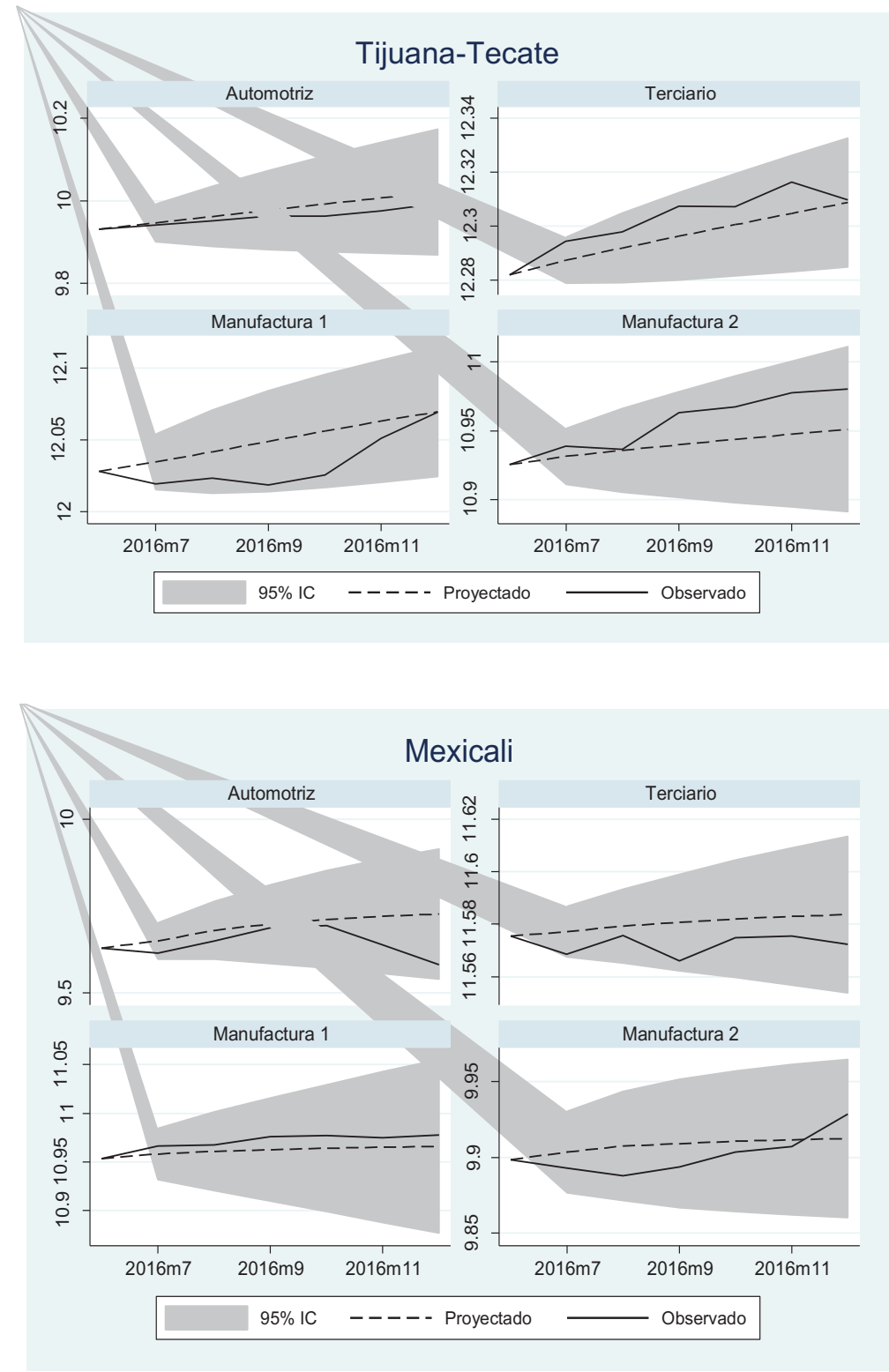

Logaritmo natural del empleo. Observado —— Pronóstico ------ 


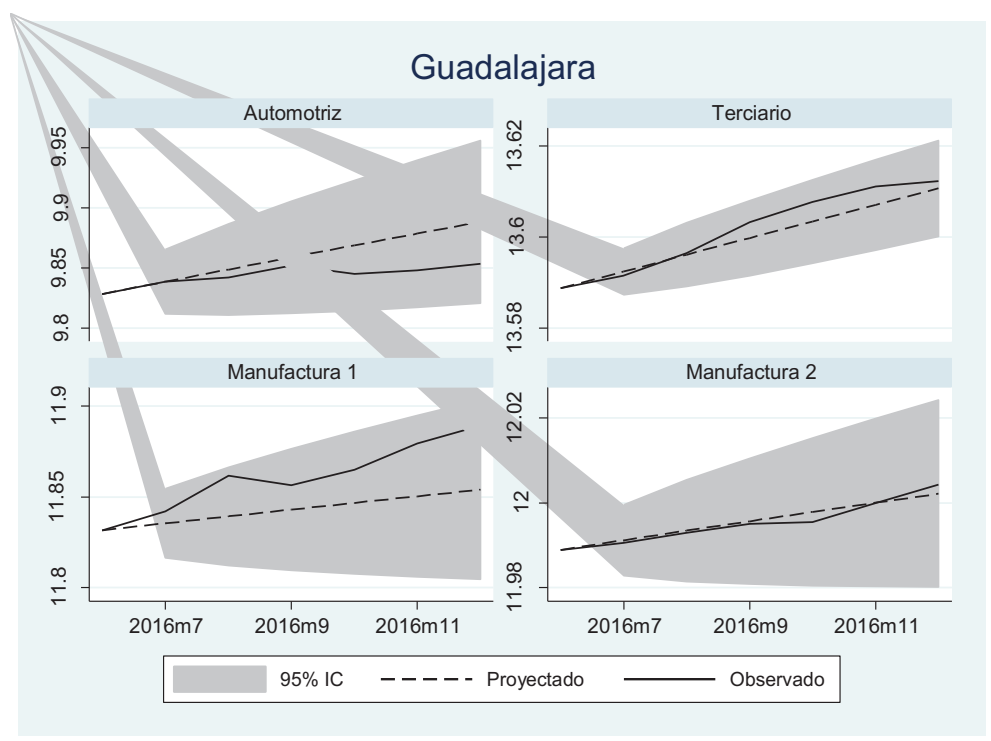

Cuadro A1. Cambios en el empleo automotriz bajo los distintos escenarios, segundo semestre de 2016

\begin{tabular}{|l|c|c|c|c|c|c|c|c|}
\hline \multicolumn{1}{|c|}{ ZONA } & OCURRIDO & $\%$ & ESC. 1 & $\%$ & ESC. . & $\%$ & ESC. 3 & $\%$ \\
\hline Aguascalientes & 2,378 & 7.7 & $-3,082$ & -10.0 & $-5,701$ & -18.5 & $-7,273$ & -23.6 \\
\hline Mexicali & -709 & -4.7 & $-1,520$ & -10.0 & $-3,967$ & -26.1 & $-3,587$ & -23.6 \\
\hline Tijuana-Tecate & 1,314 & 6.4 & $-2,055$ & -10.0 & $-4,296$ & -20.9 & $-4,851$ & -23.6 \\
\hline Saltillo-Ramos & 3,373 & 4.9 & $-6,910$ & -10.0 & $-14,856$ & -21.5 & $-16,307$ & -23.6 \\
\hline Chihuahua & 239 & 1.0 & $-2,458$ & -10.0 & $-11,309$ & -46.0 & $-5,802$ & -23.6 \\
\hline Silao-Celaya-León & 2,385 & 4.2 & $-5,719$ & -10.0 & $-11,953$ & -20.9 & $-13,497$ & -23.6 \\
\hline Hidalgo & 107 & 1.5 & -695 & -10.0 & $-1,702$ & -24.5 & $-1,640$ & -23.6 \\
\hline Guadalajara & 469 & 2.5 & $-1,855$ & -10.0 & $-2,134$ & -11.5 & $-4,379$ & -23.6 \\
\hline Edo. de México & 2,153 & 7.1 & $-3,053$ & -10.0 & $-7,296$ & -23.9 & $-7,205$ & -23.6 \\
\hline Cuernavaca & -13 & -0.2 & -595 & -10.0 & $-2,975$ & -50.0 & $-1,404$ & -23.6 \\
\hline Monterrey & 3,050 & 4.0 & $-7,549$ & -10.0 & $-20,383$ & -27.0 & $-17,817$ & -23.6 \\
\hline Puebla & $-1,081$ & -2.8 & $-3,878$ & -10.0 & $-4,071$ & -10.5 & $-9,151$ & -23.6 \\
\hline Querétaro & 1,410 & 3.6 & $-3,953$ & -10.0 & $-12,886$ & -32.6 & $-9,329$ & -23.6 \\
\hline San Luis Potosí & 758 & 2.6 & $-2,945$ & -10.0 & $-7,509$ & -25.5 & $-6,950$ & -23.60 \\
\hline Hermosillo & -502 & -4.0 & $-1,261$ & -10.0 & -567 & -4.5 & $-2,976$ & -23.6 \\
\hline Total & 15,332 & 3.2 & $-47,528$ & -10.0 & $-111,607$ & -23.5 & $-112,166$ & -23.6 \\
\hline
\end{tabular}

Fuente: elaboración propia con base en estadísticas de empleo del Imss. 
174 ECONOMÍA TeOrÍA y PrÁCTICA • Nueva Época, Número especial, vol. 4, agosto 2018

Cuadro A2. Cambios en el empleo en Man1 bajo los distintos escenarios, segundo semestre de 2016

\begin{tabular}{|l|c|c|c|c|c|c|c|c|c|c|}
\hline \multicolumn{1}{|c|}{ ZONA } & OCURRIDO & \multicolumn{1}{c|}{$\%$} & ESC. 1 & \multicolumn{1}{c|}{$\%$} & ESC. 2 & $\%$ & ESC. 3 & $\%$ & ESC. 4 & $\%$ \\
\hline Aguascalientes & 319 & 1.8 & -52 & -0.3 & -150 & -0.8 & -212 & -1.2 & $-2,264$ & -12.5 \\
\hline Mexicali & 1,402 & 2.5 & -579 & -1.0 & $-1,915$ & -3.4 & $-1,698$ & -3.0 & $-7,145$ & -12.5 \\
\hline Tijuana-Tecate & 7,011 & 4.2 & 4,803 & 2.9 & 3,608 & 2.2 & 3,299 & 2.0 & $-20,924$ & -12.5 \\
\hline Saltillo-Ramos & -210 & -0.5 & $-1,689$ & -4.1 & $-3,809$ & -9.3 & $-4,204$ & -10.3 & $-5,109$ & -12.5 \\
\hline Chihuahua & -469 & -1.0 & 174 & 0.4 & -618 & -1.4 & -101 & -0.2 & $-5,685$ & -12.5 \\
\hline Silao-Celaya-León & 4,384 & 8.9 & 1,615 & 3.3 & 891 & 1.8 & 702 & 1.4 & $-6,143$ & -12.5 \\
\hline Ciudad Sahagún & 246 & 17.6 & 16 & 1.1 & -2 & -0.1 & -0 & 0.0 & -175 & -12.5 \\
\hline Guadalajara & 8,143 & 5.9 & 2,607 & 1.9 & 2,616 & 1.9 & 2,694 & 2.0 & $-17,191$ & -12.5 \\
\hline Edo. de México & 1,053 & 2.5 & -808 & -1.9 & $-1,682$ & -4.0 & $-1,662$ & -3.9 & $-5,266$ & -12.5 \\
\hline Cuernavaca & 420 & 4.3 & 84 & 0.9 & 125 & 1.3 & 96 & 1.0 & $-1,219$ & -12.5 \\
\hline Monterrey & 8,900 & 4.2 & -65 & 0.0 & $-9,230$ & -4.4 & $-7,328$ & -3.5 & $-26,374$ & -12.5 \\
\hline Puebla & 1,821 & 7.1 & 928 & 3.6 & 905 & 3.5 & 268 & 1.0 & $-3,223$ & -12.5 \\
\hline Querétaro & 5,227 & 8.4 & -188 & -0.3 & $-3,639$ & -5.9 & $-2,196$ & -3.5 & $-7,754$ & -12.5 \\
\hline San Luis Potosí & 1,281 & 3.2 & -188 & -0.5 & -957 & -2.4 & -859 & -2.14 & $-5,016$ & -12.5 \\
\hline Hermosillo & 979 & 6.3 & 78 & 0.5 & 122 & 0.8 & -39 & -0.2 & $-1,956$ & -12.5 \\
\hline Total & 40,509 & 4.4 & 6,736 & 0.7 & $-13,735$ & -1.5 & $-11,241$ & -1.2 & $-115,443$ & -12.5 \\
\hline
\end{tabular}

Fuente: elaboración propia con base en estadísticas de empleo del Imss.

Cuadro A3. Cambios en el empleo en Man2 bajo los distintos escenarios, segundo semestre de 2016

\begin{tabular}{|l|r|r|r|r|r|r|r|r|r|r|}
\hline \multicolumn{1}{|c|}{ ZONA } & OCURRIDO & \multicolumn{1}{c|}{$\%$} & \multicolumn{1}{c|}{ ESC. 1 } & \multicolumn{1}{c|}{$\%$} & ESC.2 & \multicolumn{1}{c|}{$\%$} & ESC. 3 & $\%$ & ESC. 4 & $\%$ \\
\hline Aguascalientes & 347 & 1.0 & -168 & -0.5 & -367 & -1.1 & -494 & -1.4 & -714 & -2.1 \\
\hline Mexicali & 614 & 3.1 & 393 & 2.0 & 609 & 3.1 & 573 & 2.9 & 102 & 0.5 \\
\hline Tijuana-Tecate & 3,133 & 5.6 & 1,047 & 1.9 & 778 & 1.4 & 708 & 1.3 & 2,118 & 3.8 \\
\hline Saltillo-Ramos & $-1,203$ & -5.6 & $-1,259$ & -5.8 & $-1,651$ & -7.6 & $-1,728$ & -8.0 & $-1,465$ & -6.8 \\
\hline Chihuahua & 376 & 1.6 & 63 & 0.3 & -226 & -0.9 & -37 & -0.2 & 6 & 0.0 \\
\hline Silao-Celaya-León & 936 & 0.8 & 1,104 & 0.9 & 343 & 0.3 & 141 & 0.1 & $-1,024$ & -0.8 \\
\hline Ciudad Sahagún & 7 & 1.0 & -9 & -1.2 & 14 & 2.0 & 13 & 1.8 & 5 & 0.7 \\
\hline Guadalajara & 2,513 & 1.6 & 1,170 & 0.7 & 1,093 & 0.7 & 430 & 0.3 & 1,460 & 0.9 \\
\hline Edo. de México & 1,378 & 1.6 & 73 & 0.1 & -631 & -0.7 & -615 & -0.7 & $-1,463$ & -1.6 \\
\hline Cuernavaca & 305 & 2.0 & 15 & 0.1 & 290 & 1.9 & 95 & 0.6 & 145 & 0.9 \\
\hline Monterrey & 811 & 0.5 & 738 & 0.5 & 186 & 0.1 & 300 & 0.2 & $-1,061$ & -0.7 \\
\hline
\end{tabular}




\begin{tabular}{|l|r|r|r|r|r|r|r|r|r|c|}
\hline Puebla & 127 & 0.2 & 2,208 & 4.2 & 2,224 & 4.2 & 2,681 & 5.1 & 2,600 & 5.0 \\
\hline Querétaro & 1,129 & 3.4 & -402 & -1.2 & $-1,869$ & -5.6 & $-1,259$ & -3.8 & $-1,695$ & -5.1 \\
\hline San Luis Potosí & 336 & 1.1 & -270 & -0.9 & -664 & -2.1 & -613 & -1.95 & -691 & -2.2 \\
\hline Hermosillo & 71 & 0.5 & 57 & 0.4 & 53 & 0.4 & 68 & 0.5 & 25 & 0.2 \\
\hline Total & 10,879 & 1.3 & 4,760 & 0.6 & 183 & 0.02 & 262 & 0.03 & $-1,654$ & -0.2 \\
\hline
\end{tabular}

Fuente: elaboración propia con base en estadísticas de empleo del Imss.

Cuadro A4. Cambios en el empleo terciario bajo los distintos escenarios, segundo semestre de 2016

\begin{tabular}{|l|c|c|c|c|c|c|c|c|c|c|}
\hline \multicolumn{1}{|c|}{ ZONA } & OCURRIDO & $\%$ & ESC. 1 & $\%$ & ESC. 2 & $\%$ & ESC. 3 & $\%$ & ESC. 4 & $\%$ \\
\hline Aguascalientes & 1,400 & 1.0 & $-1,716$ & -1.2 & $-3,573$ & -2.5 & $-4,746$ & -3.4 & $-5,881$ & -4.2 \\
\hline Mexicali & -342 & -0.3 & -168 & -0.2 & -907 & -0.9 & -786 & -0.7 & $-1,464$ & -1.4 \\
\hline Tijuana-Tecate & 6,090 & 2.8 & 4,951 & 2.3 & 4,524 & 2.1 & 4,413 & 2.0 & 6,645 & 3.1 \\
\hline Saltillo-Ramos & 2,326 & 2.3 & 1,552 & 1.5 & 217 & 0.2 & -39 & -0.04 & 281 & 0.3 \\
\hline Chihuahua & 785 & 0.6 & 245 & 0.2 & -877 & -0.7 & -143 & -0.1 & 24 & 0.02 \\
\hline Silao-Celaya-León & $-5,128$ & -1.8 & $-1,672$ & -0.6 & $-5,286$ & -1.8 & $-6,227$ & -2.2 & $-3,744$ & -1.3 \\
\hline Hidalgo & 74 & 1.9 & 55 & 1.5 & 75 & 2.0 & 73 & 1.9 & 46 & 1.2 \\
\hline Guadalajara & 19,015 & 2.4 & 14,517 & 1.8 & 14,241 & 1.8 & 11,868 & 1.5 & 15,037 & 1.9 \\
\hline Edo. de México & 3,231 & 1.7 & 2,754 & 1.4 & 621 & 0.3 & 670 & 0.4 & $-3,046$ & -1.6 \\
\hline Cuernavaca & -334 & -0.3 & 960 & 0.9 & 253 & 0.2 & 755 & 0.7 & 1,133 & 1.1 \\
\hline Monterrey & 14,113 & 1.8 & 9,945 & 1.2 & $-1,192$ & -0.1 & 1,134 & 0.1 & $-7,893$ & -1.0 \\
\hline Puebla & 8,956 & 3.6 & 6,805 & 2.7 & 6,785 & 2.7 & 6,246 & 2.5 & 4,849 & 1.9 \\
\hline Querétaro & 4,335 & 1.9 & 5,219 & 2.3 & 3,074 & 1.3 & 3,965 & 1.7 & 1,950 & 0.9 \\
\hline San Luis Potosi & $-1,116$ & -1.0 & -257 & -0.2 & $-1,030$ & -0.9 & -930 & -0.81 & $-1,981$ & -1.7 \\
\hline Hermosillo & 2,351 & 1.8 & 1,645 & 1.3 & 1,641 & 1.3 & 1,665 & 1.3 & 1,589 & 1.2 \\
\hline Total & 55,757 & 1.6 & 44,836 & 1.2 & 18,568 & 0.5 & 17,918 & 0.5 & 7,545 & 0.2 \\
\hline
\end{tabular}

Fuente: elaboración propia con base en estadísticas de empleo del IMss. 
